\title{
In-situ Observation of Crack Nuclei in Poly-granular Graphite under Ring-on-Ring Equi-Biaxial and Flexural Loading*
}

\author{
M. Mostafavi ${ }^{1 \dagger}$, T.J. Marrow ${ }^{1,2}$ \\ ${ }^{1}$ Materials Performance Centre, The University of Manchester, Manchester, UK \\ ${ }^{2}$ Oxford Martin School, Department of Materials, University of Oxford
}

\begin{abstract}
Fracture tests of graphite are known to exhibit sensitivity to stress state, such as a difference between their flexural and tensile strengths. Bi-axial tensile and flexural loading are representative of the stress states in some regions of graphite components in nuclear fission reactors, where loading develops from fast neutron irradiation-induced dimensional change and thermal strains. Study of the behaviour of the inherent defects that determine strength variability requires in-situ observation of crack nucleation. To this end, digital image correlation can be used to monitor the evolution of displacement fields and hence the cracks on the surface of large samples whilst under load. In this study, a ring-on-ring flexural test setup was developed to apply equi-biaxial tensile stress to large disc specimens of graphite along with the conventional four-point-bend test. A $17 \%$ reduction in mean flexural strength was observed for the equi-biaxial loading, relative to uniaxial loading. DIC was used to
\end{abstract}

\footnotetext{
* NOTICE: this is the author's version of a work that was accepted for publication in Engineering Fracture Mechanics. Changes resulting from the publishing process, such as peer review, editing, corrections, structural formatting, and other quality control mechanisms may not be reflected in this document. Changes may have been made to this work since it was submitted for publication. A definitive version was subsequently published in Engineering Fracture Mechanics Volume 78, Issue 8, May 2011, Pages 1756-1770, DOI: 10.1016/j.engfracmech.2010.11.004

$\dagger$ Corresponding author -Materials Performance Centre, The Mill, Sackville Street, The University of Manchester, Manchester, M13 9PL UK

Email: M.Mostafavi@Manchester.ac.uk

Tel: +44 (0)1613062943

Fax: +44 (0)161306 3586
} 
characterise the observed fracture nuclei. Linear elastic fracture mechanics analysis was shown to be inadequate to explain the strength reduction. It is suggested that fictitious crack models, originally developed to simulate the behaviour of concrete structures, can be utilised to explain the behaviour.

Keywords: Graphite, Digital Image Correlation, Finite Element Method, Multiaxial Fracture, Cohesive Zone Model

\section{NOMENCLATURE}

$a$

Crack depth

c

Half the crack length

$d$

Movement towards camera

$d_{r}$

Radial displacement

$h$

Specimen height

$i$

Specimen number

$k$

Crack geometry factor

$r$

Opening ratio

$\bar{r}, \theta, z$

Conventional cylindrical coordinates with origin at the centre of the 
disc specimen

$t$

$x, y$

$C_{10}, C_{01}, D_{1}$

D

E

$E^{\prime}$

$G_{f}$

$K_{I}$

$N$

$P$

$P_{f}$

$P_{c}$
Specimen thickness

Conventional Cartesian coordinates with origin at the centre of the rectangular specimen

Hyperelastic material properties

Relative displacement of two windows on either side of a detected crack

Young's modulus

Apparent elastic modulus

Separation energy

Mode I stress intensity factor

Number of tested specimens

Load

Fracture probability

Fracture load 
Specimen radius in ring-on-ring test configuration

$R_{i}$

Inner support radius in ring-on-ring test configuration

$R_{o}$

Outer support radius in ring-on-ring test configuration

$S$

Specimen geometry factor

$S_{i}$

Half the inner span in four point bend test configuration

$S_{o}$

Half the outer span in four point bend test configuration

$Y_{I}$

Normalised mode I stress intensity factor

$W$

Specimen width

$v$

Poisson's ratio

$\delta$

Crack mouth opening displacement

$\sigma_{c}$

Critical principal stress

$\sigma_{f}$

Flexural strength

$\sigma_{b}$

Bending stress 


\section{INTRODUCTION}

Graphite is used in several designs of nuclear fission reactors such as the Advanced Gas Reactors (AGR) in the UK, the Pebble Bed Modular Reactor (PBMR) and proposed high temperature Generation IV designs as a neutron moderator and reflector. Its structural integrity is important for safe operation, as irradiation-induced dimensional strains and thermal strains cause tensile stress, and irradiation can be detrimental to strength. Crack nucleation may therefore occur with prolonged operation.

One element required for evaluation of the graphite fracture behaviour under realistic loading conditions is an understanding of the effect of stress state on strength. Test specimens of quasi-brittle materials, such as nuclear graphite, are well known to exhibit sensitivity to stress state [1]. The behaviour of nuclear graphite under equi-biaxial loading condition is of interest since biaxial stress is representative of the loading in some regions of graphite components [2].

A wide range of models have been proposed for the fracture of graphite, from the simple model suggested by Tucker [3] to the more complex Burchell model [4]. Burchell later expanded his probabilistic model to include the effects of multiaxial (hoop and tensile/compressive axial) loading by considering the difference between the average number of pores being loaded under biaxial loading compared to uniaxial loading [5]. Awaji and co-workers [6] introduced a critical shear stress as well as the critical principal stress to account for the multiaxial tensile/shear loading.

The widely accepted deterministic theory for fracture of graphite defines a critical maximum principal stress [6]. However, due to the heterogeneity of graphite, the local maximum principle stress distribution can be noticeably different in similar specimens under identical loading condition. Therefore, knowledge of both the size and spatial 
distributions of significant flaws in the microstructure is important. Observation of surface-breaking flaws can be achieved through in-situ observation of the full-field displacements on the surface of samples, such as via electronic speckle pattern interferometry [7] and digital image correlation (DIC) [8]. DIC is based on recognizing and comparing specific features in both deformed and undeformed bodies to calculate their displacement [9]. By differentiating the displacement field, the strain field can be obtained. The distortions in the strain field due to surface breaking flaws makes their detection possible. The DIC technique was utilised in this investigation to locate the nucleation, and study the initial propagation, of the fracture initiator.

Several methods can be used to induce a biaxial stress field. A cruciform specimen under two perpendicular loadings is a common method [10]. A disadvantage is that crack initiation may not take place on the surface, which is essential for DIC analysis. In addition, controlling two sets of actuators to apply equi-biaxial loading in displacement control mode is difficult. A simpler method is to use the flexural ring-onring loading configuration [11]. This has been developed in the present study to produce an equi-biaxial stress field, which has constant magnitude in all radial directions.

Linear elastic fracture mechanics has been used to assess the fracture resistance of graphite specimens [12-15]. However, its validity in the assessment of graphite components is uncertain because of an inability to explain behaviours such as the dependence of the toughness on the stress state [1], specimen size [16], specimen geometry $[17,18]$, the nonlinearity observed in the tensile tests [19] and $J$-resistance behaviour $[20,21]$ (i.e. rising fracture resistance with crack propagation). The nonlinear behaviour of graphite can be attributed to the observed mechanisms of micro-cracking [22] and crack bridging [23]. In this work, it is suggested that models that consider softening behaviour before final fracture should be utilised to simulate fracture behaviour of polygranular graphite. Fictitious crack theory, originally developed to simulate the behaviour of concrete structures [24], considers a cohesive zone in front of 
the crack tip. A finite element analysis has been employed to predict the relationship between the strength of specimens under uniaxial and equi-biaxial loading, and comparison has been made with the experimental results. Digital image correlation was used to monitor and analyse the nucleation and propagation of cracks, and the measurements of crack opening displacements are compared with the model predictions.

\section{FINITE ELEMENT STUDY}

Previous experimental investigations showed that damage in medium to coarse grained polygranular nuclear graphite under flexural loading propagates from small surface defects [8], of the order of $1 \mathrm{~mm}$ in size. Assuming that these can be approximated as semi-elliptical cracks, models of crack behaviour under uniaxial four-point-bend and biaxial flexure, were created using Abaqus/standard V. 6.9 [25]. Figure 1a illustrates a typical semi-elliptical crack where $a$ is the crack depth and $c$ is half of the crack length. Figure $1 \mathrm{~b}$ and Figure 1c show the FE mesh of uniaxial and equi-biaxial models respectively with a semi-elliptical crack $(2 c=10 \mathrm{~mm}$ and $a=2 \mathrm{~mm})$. The dimensions of the models are reported in Table 1. The equi-biaxial model corresponds to the experiment (see section 3) and the uniaxial model dimensions were selected to achieve geometrical similarity between the two models. The dimensions of the crack are representative of typical defects in nuclear graphite [7].

Using symmetry, one quarter of each sample was modelled with appropriate boundary conditions. The graphite was defined as a linear elastic material with typical mechanical properties $E=10900 \mathrm{MPa}$ and $v=0.21$ [26]. The supports were hyperelastic rubber (see section 3.3), defined by the Mooney-Rivilin equation with values $C_{10}=3.2$, $C_{0 I}=0.8$ and $D_{I}=1$. To verify the basic elastic model, the predicted stress distribution on the tensile surface of non-cracked samples was compared with analytical solutions [27]. The agreement was within $2 \%$. A concentrated mesh with collapsed elements was used at the crack tip (Figure 1d). Singular elements (with middle nodes at $1 / 4$ of the element 
edge) were not employed. Such elements affect the energy release rate only over the first few contours [28], and were unnecessary. The mesh was loaded by applying a displacement to a rigid body that was in contact with the rubber supports. These were in contact with the graphite sample. A total number of 14649 quadratic brick elements were used to simulate the disc specimen and 29210 similar elements were employed for the rectangular specimen.

The applied displacements were selected to apply an equal bending stress (axial stress for uniaxial and radial stress for biaxial samples) at the surface of both models. Since the applicability of LEFM to predict the effects of stress state on fracture is to be tested, the mode I stress intensity factor $K_{I}$ along the crack front was calculated using Abaqus through the contour integral method [28], and was normalised using Eq. (1):

$$
Y_{I}=\frac{K_{I}}{\sigma_{b} \sqrt{a}}
$$

where $Y_{I}$ is the normalised mode I stress intensity factor, $\sigma_{b}$ is the bending stress and $a$ is the crack depth. The resulting stress intensity factors of two models with rigid and rubber supports were compared, finding no meaningful difference, so the effects of changing the properties of the supports are local.

It should be noted that the configuration of the equi-biaxial test in this study differs from a conventional centre crack specimen under orthogonal biaxial stress [29]. In that case, load applied parallel to the crack faces only changes the in-plane constraint and has no effect on the opening stress. The stress intensity factor variation along the crack front would therefore be the same as uniaxial loading [10] (if the Poisson's effect is neglected). In the equi-baxial ring-on-ring geometry a radially constant stress field is applied. This changes the in-plane as well as the out-of-plane constraint and therefore affects the crack opening behaviour. 
Figure 2a shows the normalised mode I stress intensity factor obtained for the uniaxial and equi-biaxial conditions. The stress intensity factor is highest at the surface for each case. For equi-biaxial loading, the stress intensity factor is significantly higher (five times) at the surface than the deepest point of the crack, indicating a strong tendency for crack propagation along the surface.

It is well known that the crack tip stress field singularity at a corner point (i.e. where the crack intersects the free surface of the specimen) differs from the theoretical $1 / \sqrt{\bar{r}}$ relationship $(\bar{r}$ is the distance from the crack tip) provided that $v>0$. This issue has been addressed by many researchers (e.g. Benthem [30], Nakamura and Parks [31] and more recently He and Hutchinson [32]). Stress intensity factors may be calculated for a singular field with a known singularity (e.g. $[33,34])$. However, such methods can result in erroneous stress intensity factors at corner points due to the difference between the assumed singularity and the actual singularity, which is weaker at the corner points. This problem has led researchers to dismiss SIFs calculated at the corner points in FE analyses (e.g. Pook [35]). For continuous crack fronts, such as semi-elliptical cracks, extrapolation of the SIF is suggested [33], using the trend at some distance from the corner point where the stress field is of $1 / \sqrt{\bar{r}}$ singularity. However, SIF's presented in Figure 2a were calculated from Eq.(2) using the domain integral method, instead.

$K_{I}=\sqrt{J E^{\prime}}$

where $E^{\prime}$ is apparent elastic modulus which is equal to $E$ for plane strain and $E /\left(1-v^{2}\right)$ for the plane stress conditions. $J$ is the energy release rate calculated by the domain integral method [25]. The domain integral method is not dependent on a presumed singularity thus its use does not need to be restricted to a crack front that intersects the free surface at a specific angle (dependent on Poisson's ratio) to ensure $1 / \sqrt{\bar{r}}$ singularity. Furthermore, in mode I loading there is no need to use auxiliary fields (which are again based on a defined singular stress or strain field [36]) to break down the calculated energy release rate to 
mode I, mode II, mode III stress intensity factors and $T$-stress. The stress intensity factors calculated in this FE model showed no mode II or mode III contributions.

The stress intensity factors under uniaxial flexural loading, obtained in this way from the FE model, were compared with the values obtained by Newman and Raju [37] from a $3 \mathrm{D}$ FE analysis for the same crack geometry. There is agreement (within 15\%) between the two analyses. Newman and Raju's stress intensity factor solution [38] is based on the nodal force method [39] while our solution is based on the domain integral method [28], which may explain the small difference between the uniaxial solutions. The stress intensity factors in both uniaxial and equi-biaxial cases were calculated using the same domain integral method to ensure consistency.

Assuming the mode I LEFM stress intensity factor controls crack propagation, simple analysis of equivalent cracks suggests a significant effect of stress state would be expected, with surface propagation under biaxial loading occurring at approximately $78 \%$ of the uniaxial stress, and depth propagation at approximately $250 \%$. The latter would determine failure strength. This is unrealistic and also very different from the results of the Burchell multiaxial model [5] which predicts only $4 \%$ reduction in the case of equi-biaxial stress.

Alternatively, Sato and co-workers [40] have suggested that the maximum principal stress can be used to estimate the expected difference between the strength of structures under uniaxial and biaxial loadings. Hence, the maximum principal stress ahead of the crack front, at a nominal distance of $1 \mathrm{~mm}$, was extracted from the FE model (Figure $2 b$ ). This distance was selected as being of the same order as the microstructure length scale, and hence comparable to a representative volume [7]. Despite the considerable difference between the stress intensity factors, the maximum principal stresses, which are highest at the surface, are very similar $(<7 \%)$ at this position under both uniaxial and equi-biaxial conditions. No significant effect of stress state would therefore be expected from this simple model, which is inconsistent with our experimental findings (see Section 3). 
The $T$-stress was not used in the present study, although it has been proposed by other researchers investigating mixed mode loading in graphite (e.g. [13]). This is because in both cases considered here the crack is under pure mode I loading. T-stress does not have any effect on the opening stress in pure mode I [41], and may therefore be neglected in this analysis. In the next section, comparison between FE predictions of crack behaviour and experimental observations is made.

\section{EXPERIMENTS}

Experiments were carried out to first calibrate the effects of relative vertical displacements on DIC displacement measurement, and then to perform four point bend uniaxial and ring-on-ring equi-biaxial fracture tests to detect crack nuclei and their propagation. The test setup is shown in Figure 3. Figure 3a shows the overview of the test setup, Figure $3 \mathrm{~b}$ the disc specimen and Figure $3 \mathrm{c}$ the coordinates. A 4MPixel 14 bit camera with a $50 \mathrm{~mm}$ objective lens was used to monitor the area of constant bending moment on each sample (approximately $100 \mathrm{~mm} \times 100 \mathrm{~mm}$ ).

\subsection{Calibration Tests}

The calibration tests were conducted using PMMA (i.e. Perspex). PMMA samples were loaded in both uniaxial and equi-biaxial geometries, with the same dimensions as the graphite test specimens. In flexural testing, the samples deflect noticeably in the centre. Parallax effects due to displacement towards the camera cause an artificial strain field in the DIC analysis. This was calibrated by moving an unloaded disc toward the camera (the distance is denoted by symbol $d$ ) to calculate the apparent strain. Figure 4 shows the resulting strain in one direction $\left(\varepsilon_{x x}\right)$, calculated by DIC for a window size of $128 \times 128$ pixels, with $0 \%$ overlap. There was no significant difference between the apparent strains in the orthogonal directions. The effect of moving a constant tilted surface (up to 20 degrees) was also found to be negligible in comparison to other strains. 


\subsection{Uniaxial Fracture Testing}

Fourteen four-point-bend uniaxial graphite samples were tested at a displacement rate of $0.2 \mathrm{~mm} / \mathrm{min}$. Each specimen measured $(2 W \times 2 h \times t) 200 \mathrm{~mm} \times 100 \mathrm{~mm} \times 10 \mathrm{~mm}$, with inner $\left(S_{i}\right)$ and outer $\left(S_{o}\right)$ spans of $90 \mathrm{~mm}$ and $180 \mathrm{~mm}$ (see Figure 1b). The support rollers were stainless steel, for convenience. As noted earlier, the FE analysis showed that changing the steel supports to rubber caused less than $7 \%$ difference in the strain field at the points of contact, with negligible effects elsewhere. Images were recorded at $1 \mathrm{~Hz}$ (typically 500 images per test). Focus was maintained at a position approximately $30 \mathrm{~mm}$ longitudinally from the sample centre. The flexural strength $\left(\sigma_{f}\right)$ was calculated using Eq. 3.[42]:

$\sigma_{f}=\frac{3 P_{c}\left(S_{o}-S_{i}\right)}{h t^{2}}$

where $P_{c}$ is the load at fracture.

\subsection{Biaxial Fracture Testing}

Nine disc shaped graphite samples were tested using a ring-on-ring configuration. The diameter $(2 R)$ of the samples was $350 \mathrm{~mm}$. The diameters of the inner $\left(2 R_{i}\right)$ and outer $\left(2 R_{o}\right)$ support rings were $150 \mathrm{~mm}$ and $300 \mathrm{~mm}$. Viton rubber O-rings $(8 \mathrm{~mm}$ in crosssection diameter) were used as supports to minimize the contact stresses, which was particularly important for these large specimens. The displacement and imaging conditions were as before, with typically 2000 images per test. The flexural strength was calculated using Eq. (4)[27]:

$\sigma_{f}=\frac{3(1+v)}{2 \pi t^{2}} P_{c}\left[\ln \left(\frac{R_{o}}{R_{i}}\right)+\frac{(1-v)\left(R_{o}^{2}-R_{i}^{2}\right)}{(1+v) 2 R^{2}}\right]$ 
Following testing, Eq. (5) was employed to calculate the probability of fracture as a function of flexural strength (Figure 5). An average mean strength reduction of $17 \%$ was observed between the uniaxial and equi-biaxial conditions.

$P_{f}=\frac{i-0.5}{N}$

where $P_{f}$ is the fracture probability, $N$ is the total number of tested samples and $i$ is the sample number, ranked in strength.

\section{DIC ANALYSIS}

DIC was used to evaluate the evolution of surface displacements and to detect crack nucleation and propagation by analysis of the strain field. In order to carry out such analysis, the LA Vision Davis software was used (Version 7.2) [43]. Multiple interrogation analysis with a window size of $256 \times 256$ pixels at an overlap of $0 \%$ with 2 passes, followed by $64 \times 64$ pixel windows at an overlap of $25 \%$ with 4 passes was found to give the best results in terms of image resolution and displacement accuracy.

\subsection{Calibration}

The measured surface strain field for a PMMA sample under equi-biaxial flexure was compared to the analytical solution [27] to verify the test procedure and also the DIC analysis. Typical properties of PMMA ( $E=3100$ MPA, $v=0.35)$ were assumed [44]. For example, the radial strain $\left(\varepsilon_{r r}\right)$, between the inner and outer supports is calculated to be $0.1465 \%$ [27] at a load $P=1240 \mathrm{~N}$, which was the maximum load applied. Figure 6 shows a good correlation between the predicted (i.e. analytical) and measured (i.e. DIC) strain, although there are discrepancies, particularly towards the edge of the observed region where the measured strain is lower than predicted (approximately 16\%). 
At the maximum load, the centre of the PMMA sample was calculated [27] to be 0.3 $\mathrm{mm}$ closer to the camera than the support positions. The calibration experiments (Figure 4) recorded an apparent strain of 0.002105 per $\mathrm{mm}$ of relative displacement, which was therefore used to correct the raw DIC data. The focus position $(30 \mathrm{~mm}$ from the centre) was taken as reference for the correction. A corrected strain profile for the PMMA specimen is shown in Figure 6, which shows the effect of curvature is real but is small compared to the experimental noise. The experimental noise $(0.024 \%)$ was estimated from the RMS error in strain obtained by DIC analysis of successive images recorded of a sample with no load change, and was similar for both PMMA and graphite specimens. This noise level is represented by the error bars in Figure 6 .

\subsection{Crack Detection}

An example of the evolution of a crack in uniaxial flexural loading experiment observed by DIC is shown in Figure 7, which is a map of the maximum principal strain on the tensile surface. That of a disc specimen under equi-biaxial flexural loading is shown in Figure 8. Note that the dark features observed in the strain maps, which grow as the loading increases, show the areas of high strain. These are interpreted as surface breaking discontinuities (i.e. cracks) in this work. The observed maximum principal strain is a measure of the crack opening displacement, which is visualised readily using the calculated strain field. Accuracies are: in-plane surface displacement measurement $2 \mu \mathrm{m}$, crack length measurement $0.02 \mathrm{~mm}$, and bending stress $0.05 \mathrm{MPa}$. In both cases, the background strain field due to the curvature-induced displacement of the sample towards the camera is observable, but it is small in magnitude compared to the strains associated with cracks. Cracks could be detected prior to failure on the surface of both uniaxial and equi-biaxial samples as regions of high apparent strain (typically $1 \%$ and $1.5 \%$ respectively). Cracks were first observed by DIC at around the same stresses at which audible acoustic emission occurred, which was around $90 \%$ of the failure load. In six cases (three uniaxial and three biaxial) of the total 20 tests, the nucleation and propagation of the crack responsible for the final failure was clearly observable by DIC. 
These six cases are the focus of the rest of this paper. In the remaining of the specimens, no crack was detected on the surface of the specimen where final fracture occurred suggesting either a subsurface defect was responsible for the failure, or more likely from defects with a surface breaking length of less than 1-2mm, which was the spatial resolution at which features emerged above the background noise [8].

\subsection{Crack Length and Opening Displacements}

DIC analysis allows the evolution of crack surface length and maximum opening displacement to be studied prior to failure of the test specimen under different loading states. As discussed above, significant local increases in the observed maximum principal strain field are an indication of a displacement field discontinuity, which is interpreted as the opening of a crack nucleus. A MATLAB ${ }^{\circledR}$ code was developed to identify groups of pixels in the image with strains above a threshold (1\% for uniaxial and $1.5 \%$ for biaxial). The thresholds were selected to be $25 \%$ higher than the approximately constant background noise within the inner supports. To study the sensitivity of the measured crack lengths on the selected threshold, the threshold was increased by $50 \%$, which resulted in reduction of the calculated surface crack length of less than $10 \%$. It was therefore concluded that the measured surface crack length is weakly dependent on the threshold, and a constant threshold criteria was appropriate. The crack length was evaluated as the end-to-end distance of the group of connected pixels. Figure 9 shows data for the longest detected crack in three examples of each specimen geometry as the applied stress increases. It shows that cracks nucleate and propagate along the surface, but there is no apparent relationship between surface crack length and flexural strength. It can be seen in this figure that cracks are generally first detected when they were between 1-2 mm long. The smallest detected crack was 2.4 $\mathrm{mm}$ long in uniaxial and $1.6 \mathrm{~mm}$ for biaxial.

In flexural loading, it is the crack depth that determines strength, not the surface crack length. However, it is very difficult to experimentally measure the crack depth in graphite samples, even with post-test sectioning, due to the complex and porous 
microstructure. Measuring the crack mouth opening displacements, on the other hand, is possible using DIC, and this may be used to estimate the defect depth [8]. Assuming elastic deformation of a semi-elliptical crack, the crack opening ratio, $r$, which is the ratio of the maximum crack mouth opening displacement $(\delta)$ to the applied stress $\left(\sigma_{b}\right)$ in a finite plate under elastic bending, is given by the analytical solution [45]:

$$
\begin{aligned}
& r=\frac{\delta}{\sigma_{b}}=S \frac{4\left(1-v^{2}\right)}{E \cdot \int_{0}^{\pi / 2} \sqrt{1-k^{2} \cos \psi} d \psi} a \times \\
& {\left[1+\frac{2 a}{t} \frac{k^{2} \int_{0}^{\pi / 2} \sqrt{1-k^{2} \cos \psi} d \psi}{\left(1+k^{2}\right) \int_{0}^{\pi / 2} \sqrt{1-k^{2} \cos \psi} d \psi-\left(1-k^{2}\right) \int_{0}^{\pi / 2} \frac{1}{\sqrt{1-k^{2} \cos \psi}} d \psi}\right]}
\end{aligned}
$$

where $S$ is a specimen geometry factor which can be found in [37] and $t$ is the plate thickness. Crack depth $(a)$ and crack length $(2 c)$ are defined in Figure 1a, in which a semi-elliptical crack is illustrated and $k^{2}=1-(a / c)^{2}$ is a crack geometry factor.

By selecting example cases (i.e. $c=5 \mathrm{~mm}, a \leq 1 \mathrm{~mm}$ and $a=1 \mathrm{~mm}, c \leq 5 \mathrm{~mm}$ ), the sensitivity of the crack mouth opening to variations in the crack depth and the crack length can be shown. Typical mechanical properties of graphite were employed $(E=$ $10900 \mathrm{MPa}$ and $v=0.21$ [26]) and a plate thickness of $10 \mathrm{~mm}$ was considered. Figure 10a and Figure 10b show the effect of crack dimensions on the crack opening ratio, $r$. The figures show that this ratio has a weak dependency on the crack length for shallow cracks (that is $\mathrm{a} / \mathrm{c}<1$ ) and that it is strongly dependent on the crack depth. If shallow defects exist on the surface of graphite prior to failure [8], the crack opening ratio $(r)$ may then be used to calculate their depth, assuming linear elastic deformation.

To evaluate whether stress biaxiality affects the relation between the crack opening and crack depth, the crack opening ratio was calculated for a uniaxially loaded plate using 
the analytical uniaxial solution in Eq. (6) and also using elastic finite element models for the flexural uniaxial and equi-biaxial conditions described above. Loading conditions were selected to apply an equal flexural stress at the surface of both models, as before. Figure 10 shows the analytical solution of the crack opening ratio is independent of the applied bending stress (Eq. (6)), although the FE predictions are weakly dependent on stress. This is because of the hyper-elastic behaviour of the rubber used in the FE simulation. The difference between the analytical and FE model ratios under uniaxial loading is about $18 \%$. The difference between the uniaxial and equi-biaxial FE models is $5 \%$. The implication is that, provided that linear elastic conditions prevail, similar crack depths will give quite similar crack opening ratios for both loading geometries, and that crack depth should then be evaluated from the crack opening ratio with fair accuracy using the analytical solution.

To measure the crack mouth opening displacement (CMOD) using the DIC displacement field data, two equi-distant windows were selected on opposite sides of the detected crack at a distance of approximately $1 \mathrm{~mm}$. The relative displacements of these two windows $(D)$ were measured as the applied stress was increased. Although there is a gradient of displacement that will depend on the crack size, a study on the radial displacement field, extracted from the FE simulation, shows that for a $2 \mathrm{~mm}$ deep crack the radial displacement remains relatively constant up to $4 \mathrm{~mm}$ away from the crack face (with 7.4\%, see Figure 11b). This was tested by taking windows at different positions within this distance, which showed less than 6\% variation in CMOD. It was concluded that if the windows are positioned within $2 \mathrm{~mm}$ of the observed crack, assuming the cracks are of the order of $1 \mathrm{~mm}$ deep, that accurate crack mouth opening displacements (CMOD) would be obtained.

These measurements show an initial non-linearity, which is attributed to settling of the sample within the loading rig that affects the applied strain. Linear behaviour can then be clearly observed in Figure 11a between $40 \%$ and $80 \%$ of the fracture load. At high stresses (i.e. above $\sim 90 \%$ of the failure stress), the displacement between the windows is 
observed to deviate from linear behaviour. The difference in displacement vectors between the extrapolated linear trend and the measured value was considered the crack mouth opening displacement (CMOD).

The advantage of using this method, compared to that used previously for uniaxial flexural specimens [8], is that it does not require correction for cracks that do not lie orthogonally to the image axes, and it is therefore applicable to both specimen geometries. The crack opening displacement vectors were found to be almost perpendicular to the crack, which is consistent with mode I opening behaviour. For example for the biaxial specimen B04, the crack angle was $\varphi=57^{\circ}$ (see Figure 8f) while the measured crack opening displacement vector was at $142^{\circ}$ (i.e. $5^{\circ}$ between the normal to the crack and the displacement vector). In the other examples, the difference between the crack normal and the displacement vector was less than $8^{\circ}$. The data for the crack mouth opening displacements of the uniaxial and equi-biaxial samples are shown in Figure 11c as the crack opening ratio versus applied bending stress. The openings under uniaxial loading, measured using this method, are similar to previous experiments [8].

\section{DISCUSSION}

The observed area in these experiments is large relative to the microstructure scale. Previous work has shown that there is an intrinsic population of defects in nuclear graphites $[4,7]$ and it is assumed that the observed areas contain a sufficiently large population of defects that the tests performed are representative of the microstructure's response to stress state. The DIC analysis allows the evolution of surface crack length and crack opening displacement to be studied. It shows crack propagation along the surface prior to failure in both geometries (Figure 9), and as expected there is no relationship between surface crack length and flexural strength. In both geometries, the crack opening displacement increases significantly once the defect appears above the noise threshold, typically at about $90 \%$ of the failure stress (Figure 11c). If it is 
assumed the crack opening ratio is proportional to depth, as discussed above for the elastic analysis, then this indicates stable propagation of cracks in depth as the load increases. The maximum crack mouth opening displacements differ significantly with test geometry, averaging $0.09( \pm 0.02) \mathrm{mm}$ for four point bend tests and $0.17( \pm 0.05)$ $\mathrm{mm}$ for ring-on-ring tests. The elastic models show no significant difference between the crack opening behaviour under the two stress states, hence critical defects in the equi-biaxial sample are predicted to be significantly deeper than those in the uniaxial samples.

Defect sizes of the order of $1 \mathrm{~mm}$ are expected in this grade of nuclear graphite [46]. If the nominal elastic properties of graphite are inserted in Eq. (6), the maximum crack depths are estimated to be around $0.65( \pm 0.15) \mathrm{mm}$ in the uniaxial tests, and 1.55 $( \pm 0.45) \mathrm{mm}$ in the equi-biaxial tests. These are both of the order expected, but their difference is significant. Given the large area of observation, the use of identical methods of sample preparation and also that the samples were obtained from the same region of the same graphite block, it is expected that similar populations of defects would be sampled in these tests.

It has been reported that the nominal fracture toughness for poly-granular graphite is 1.0 $\mathrm{MPa} . \sqrt{\mathrm{m}}[47,48]$. Using this value in Eq. (1) and obtaining the stress intensity factors at the deepest point of the cracks for each case according to Figure 2, for a crack depth calculated for the maximum observed crack opening displacement with Eq. (6), the predicted failure strengths were calculated. The stress intensity factor at the deepest point was selected, as propagation from this point can lead to unstable fracture, whereas crack propagation along the surface is stable. The bending stresses at which crack propagation are expected were $\sigma_{b}=28.02 \mathrm{MPa}$ for uniaxial and $\sigma_{b}=50.08 \mathrm{MPa}$ for equibiaxial loading. The predicted uniaxial flexural strength is well within the range of the experimental results (Figure 5). However, the flexural strength under biaxial loading is significantly overestimated. 
Alternatively, if a maximum critical principal stress is employed in a similar way, a 7\% reduction in the strength will be predicted due to equi-biaxial loading compared to the uniaxial tests, which underestimates the observed effect. This inability to predict the failure strength, the larger than predicted opening displacements and also the implication from the significant increase in crack opening that stable crack growth is occurring into the depth of the sample all suggest that simple elastic models are insufficient to explain the behaviour of nuclear graphite.

There is substantial evidence that fine scale microcracking is an important mechanism in the deformation and damage development in nuclear graphites [23]. Such microcracking in other quasi-brittle materials such as concretes [49] can cause tension softening behaviour. It is suggested that a cohesive zone model [24], which considers tension softening before final fracture, should be utilised to simulate the effects of stress state on poly-granular graphite fracture. In this case, the measured crack opening ratio of the observed crack nuclei comprises both the elastic opening of the crack, and a significant inelastic contribution from crack tip processes such as microcracking. The effect of this fracture process zone on the crack opening is analogous to crack tip plastic deformation in metals. Its effect on fracture strength should depend on the criteria for development of damage in the fracture process zone, and the onset of instability. As microcracking is a deformation mode that depends on tensile opening stress, it is suggested that a principal stress criteria (such as the Rankine criterion) would be most suitable to evaluate the fracture process zone development in this quasi-brittle material. The analogue for plastic deformation would be the use of the von-Mises equivalent stress to evaluate the plastic zone development.

A preliminary analysis has been done, in which the elastic elements of the discussed FE models were replaced by brittle cracking elements capable of modelling tension softening behaviour. The properties of the elements, based on a linear tractionseparation law, were: critical principal stress at which softening starts $\sigma_{c}=28 \mathrm{MPa}$ and separation energy $G_{f}=0.23 \mathrm{MPa} . \mathrm{mm}$. The critical principal stress was selected to be the 
same as the strength of uniaxial flexural test and the separation energy the same as the energy release rate of a compact tension specimen, as suggested by Cornec et al. [50]. Figure 12 shows that including such inelastic damage causes substantial increases in crack mouth opening displacements, of the order of those observed experimentally, prior to failure. The large models of the full specimens are, unfortunately, inadequate for proper investigation of the effects of stress state due to problems of convergence. For example, Figure 12 incorrectly predicts lower opening displacements for the biaxial stress state. This is now being investigated further using cohesive element modelling. The tension-softening and increase in crack opening displacement occurs because the critical principal stress is achieved locally around the crack tip before the global applied stress reaches the critical principal stress. This occurs at an applied stress for the equibiaxial state that is $18 \%$ lower than under uniaxial stress. This approach satisfactorily explains the differences between in failure strength under uniaxial and equi-biaxial flexure, and explains the development of large crack opening displacements without crack propagation in depth. Work is in progress explore the effects of stress state more accurately, and to consider the condition for crack instability, which is required to predict failure.

\section{SUMMARY}

- The mean flexural strength of nuclear graphite under equi-biaxial ring-on-ring flexural loading is measured to be $17 \%$ lower than that for uniaxial flexural loading.

- Digital image correlation can be used to detect and analyse the development of crack nuclei in nuclear graphite under uniaxial and equi-biaxial flexural loading.

- Satisfactory interpretation of the observed opening behaviour cannot be achieved through linear elastic fracture mechanics. It is proposed that the development of a fracture process zone at the defect controls the observed opening behaviour, and that the effect of stress state may be described using principal tensile stress criteria, such as the Rankine criterion. 


\section{ACKNOWLEDGEMENTS}

The authors gratefully acknowledge the support of British Energy, part of EDF Energy, for this work under project GRA/GNSR/6041. The opinions expressed are those of the authors and not necessarily those of British Energy. The authors thank to Dr J. Duff and Mr T. Becker, Materials Performance Centre, The University of Manchester, for valuable discussions and $\mathrm{Mr} \mathrm{R}$. Delorme for his assistance with the PMMA experiments.

\section{REFERENCE}

[1] Brocklehurst JE. Concerning the fracture of graphite under different test conditions. Materials Science and Engineering. 1974;16:91-106.

[2] Knott JF. Engineering structural integrity assessment: current goals. In: Flewitt PEJ, Heyes PF, Horrocks P, Knott JF, Le May I, Pisarski H, Sharples JK, Sherry A, Tomkins B, Wright K, Yates J, editors. ESIA10: Engineering structural integrity assessment: present goals - future challenges. Chipenham and Eastbourne: EMAS, 2010.

[3] Tucker MO. The application of fracture mechanics to the notch sensitivity of graphite. Gif sur Yvette, France: IAEA; 1979.

[4] Burchell TD. A microstructurally based fracture model for polygranular graphites. Carbon. 1996;34(3):297-316.

[5] Burchell TD, Yahr T, Battiste R. Modeling the multiaxial strength of H-451 nuclear grade graphite. Carbon. 2007;45:2570-2583.

[6] Sato S, Awaji H, Kawamata K, Kumrumada A, Oku T. Fracture criteria of reactor graphite under multiaxial stresses. Nuclear Engineering and Design. 1987;103:291-300.

[7] Joyce MR, Marrow TJ, Mummery PM, Marsden BJ. Observation of microstructure deformation and damage in nuclear graphite. Engineering Fracture Mechanics. 2008;75(2):3633-3645.

[8] Li H, Duff J, Marrow TJ. In-situ observation of crack nucleation in nuclear graphite by digital image correlation. Chicago, Illinois American Society of Mechanical Engineers; 2009. 
[9] Sutton MA, McNeill SR, Helm JD, Chao YJ. Advances in two-dimensional and three-dimensional computer cision. Topics in Applied Physics. 2000;77:323-372.

[10] Mostafavi M, Smith DJ, Pavier MJ. Reduction of measured toughness due to out-of-plane constraint in ductile fracture of aluminium alloy specimens. Fatigue and Fracture of Engineering Materials and Structures. 2010;33:724-739.

[11] Morrell R. Measurement good practice guide No. 12, Biaxial flexural strength testing of ceramic materials. NPL; 1998.

[12] Lomakin EV, Zobnin AI, Berezin AV. Finding the fracture toughness characteristics of graphite materials in plane strain. Strength of Materials. 1973;7(4):8992.

[13] Ayatollahi MR, Aliha MRM. Mixed mode fracture analysis of polycrystalline graphite - A modified MTS criterion. Carbon. 2008;46(10):1302-1308.

[14] Awaji H, Sato S. A statistical theory for the fracture of brittle solids under multiaxial stresses. International Journal of Fracture. 1978;14(1):R13-R16.

[15] Marshall P, Priddle EK. The influence of specimen size and mode of loading on the fracture of graphite. Carbon. 1973;11:627-631.

[16] Sakai M, Nomoyama R. Nonlinear fracture of a polycrystalline graphite - size effect law and Irwin's similarity. In: Bradt RC, Munz D, Sakai M, White KW, editors. Fracture Mechanics of Ceramics. New York: Springer, 2005. p. 337-351.

[17] Becker TH, Marrow TJ, Tait RB. Damage, crack growth and fracture characteristics of nuclear grade graphite using the double torsion technique. In preparation. 2010.

[18] Romanoski GR, Burchell TD. The effects of specimen geometry and size on the fracture toughness of nuclear graphites. Tokai, Japan: International Atomic Energy Agency, Vienna (Austria); 1991. p. 241-248.

[19] Neighbour GB, McEnaney B, Philips M. Acoustic emission responses from cyclic loading of a nuclear graphite. Carbon. 1992;30(3):359-362.

[20] Sakai M, Urashima K, Inagaki M. Energy principle of elastic-plastic fracture and its application to the fracture mechanics of polycrystalline graphite. Journal of American Ceramics Society. 1983;66(12):868-874.

[21] Allard B, Rouby D, Fantozzi G, Dumas D, Lacroix P. Fracture behaviour of carbon materials. Carbon. 1991;29(3):457-468. 
[22] Stevens R. Fracture behaviour and electron microscopy of a fine grained graphite. Carbon. 1971;9:573-578.

[23] Hodgkins AD, Marrow TJ, Mummery P, Marsden B, Fok A. X-ray tomography observation of crack propagation in nuclear graphite. Materials Science and Technology. 2006;22(9):1045-1051.

[24] Hillerborg AM, Modeer M, Petersson PE. Analysis of crack formation and crack growth in concrete by means of fracture mechanics and finite elements. Cement and Concrete Research. 1976;6:773-782.

[25] ABAQUS. User's Manual. ABAQUS Inc., Providence, Rhode Island, Version $6.9,2008$.

[26] Hodgkins AD. Crack propagation in nuclear graphite. Manchester: The University of Manchester, Ph.D. Thesis; 2006.

[27] Timoshenko S, Woinowsky-Krieger S. Theory if plates and shells. New York: McGraw-Hill, 1959.

[28] Li FZ, Shih CF, Needleman A. A comparison of methods for calculating energy release rates. Engineering Fracture Mechanics. 1985;21(2):405-421.

[29] Jones DL, Poulose PK, Liebowitz H. The effects of biaxial loading on the fracture characteristics of several engineering materials. Engineering Fracture Mechanics. 2003;24(2):187-205.

[30] Benthem JP. State of stress at the vertex of a quarter-infinite crack in a half space. International Journal of Solids and Structure. 1977;15:405-426.

[31] Nakamura T, Parks DM. Three-dimensional stress field near the crack front of a thin elastic plate. Journal of Applied Mechanics. 1988;55(4):805-809.

[32] He MY, Hutchinson JW. Surface crack subject to mixed mode loading. Engineering Fracture Mechanics. 2000;65:1-14.

[33] Pook LP. A note on corner point singularities. International Journal of Fracture. 1992;53:R3-R8.

[34] Hayashi K, Abe H. Stress intensity factors for a semi-elliptical crack in the surface of a semi-infinite body subjected to linearly varying pressure on the crack surface. International Journal of Fracture. 1979;15:R171-R174.

[35] Pook LP. Some implications of corner point singularities. Engineering Fracture Mechanics. 1994;48(3):367-378. 
[36] Dunham RS, Stern M, E.B. B. A contour integral computation of mixed mode stress intensity factors. International Journal of Fracture. 1976;12:359-368.

[37] Newman JC, Raju IS. An empirical stress-intensity factor equation for the surface crack. Engineering Fracture Mechanics. 1981;15(1-2):185-192.

[38] Newman JC, Raju IS. Stress intensity factors for a wide ranges of semi-elliptical surface cracks in finite thickness plates. Engineering Fracture Mechanics. 1979;11:817829.

[39] de Morias AB. Calculation of stress intensity factors by the force method. Engineering Fracture Mechanics. 2007;74:739-750.

[40] Sato S, Awaji H, Kawamata K, Oku T. Fracture criteria of reactor graphite under multiaxial stresses. Nuclear Engineering and Design. 1987;103:291-300.

[41] Smith DJ, Ayatollahi MR, Pavier MJ. The role of T-stress in brittle fracture for linear elastic materials under mixed mode loading. Fatigue and Fracture of Engineering Materials and Structures. 2001;24:137-150.

[42] Timoshenko S, Goodier JN. Theory of Elasticity. New York: McGraw-Hill, 1970.

[43] DaVis. User's Manual. Gottingen: LaVision $\mathrm{GmbH}, 2009$.

[44] Kourtesis G, Renwick GM, Fischer-Cripps AC. Mechanical property characterization of a number of polymers using uniaxial compression and spherical tipped indentation tests. Journal of Mechanical Science. 1997;32:4493-4500.

[45] Feng DZ, Hong QC. Investigation of surface crack opening displacement and its application in pressure vessels and piping. International Journal of Pressure Vessels and Piping. 1992;52(2):227-239.

[46] Darby MI. A fracture mechanics approach to the failure of graphite in laboratory tests. International Journal of Fracture. 1976;12(5):754-757.

[47] Ouagne P, Neighbour GB, McEnaney B. Crack growth resistance in nuclear graphites. Journal of Physics D: Applied Physics. 2002;35:927-934.

[48] Shi L, Li H, Zou Z, Fok A, Marsden B, Hodgkins AD, Mummery PM, Marrow TJ. Analysis of crack propagation in nuclear graphite using three-point bending of sandwich specimens. Journal of Nuclear Materials. 2008;372(2-3):141-151.

[49] Mazars J. A description of micro- and macroscale damage of concrete structures. Engineering Fracture Mechanics. 1986;25(5-6):729-737. 
[50] Cornec A, Scheider I, Schwalbe KH. On the practical application of cohesive model. Engineering Fracture Mechanics. 2003;70:1963-1987. 


\section{TABLES}

Table 1- Dimensions of the models (thickness $t, 10 \mathrm{~mm}$, support radius $4 \mathrm{~mm}$ )

\begin{tabular}{|c|c|c|c|c|c|c|}
\hline \multicolumn{4}{|c|}{ Rectangular specimen $(\mathrm{mm})$} & \multicolumn{3}{c|}{ Disc specimen $(\mathrm{mm})$} \\
\hline $\begin{array}{c}\text { Width } \\
(2 W)\end{array}$ & $\begin{array}{c}\text { Height } \\
(2 h)\end{array}$ & $\begin{array}{c}\text { Inner support } \\
\text { span }\left(2 S_{i}\right)\end{array}$ & $\begin{array}{c}\text { Outer } \\
\text { support } \\
\text { span }\left(2 \mathrm{~S}_{o}\right)\end{array}$ & $\begin{array}{c}\text { Diameter } \\
(2 R)\end{array}$ & $\begin{array}{c}\text { Inner support } \\
\text { radius }\left(2 R_{i}\right)\end{array}$ & $\begin{array}{c}\text { Outer support } \\
\text { radius }\left(2 R_{o}\right)\end{array}$ \\
\hline 150 & 150 & 60 & 140 & 350 & 150 & 300 \\
\hline
\end{tabular}




\section{FIGURES}

Figure 1- Semi-elliptical crack (a) schematic (b) finite element model under uniaxial loading (c) finite element model under equi-biaxial loading (d) finite element details of the crack tip

Figure 2- (a) Normalised mode I Stress intensity factor and (b) Normalised maximum principal stress at $1 \mathrm{~mm}$ along the crack front for a semi-elliptical crack ( $a=2 \mathrm{~mm}, c=5$ $\mathrm{mm}$ ) under uniaxial and equi-biaxial flexural loading

Figure 3- Details of the experiment (a) Test setup (b) Disc specimen (£2 and €2 coins were put on the sample to show the size) (c) Coordinates

Figure 4- Evaluation of the strain along $\mathrm{x}$ axis vs. the vertical displacement toward the camera

Figure 5- Fracture probability of graphite in uniaxial and equi-biaxial loadings

Figure 6- Radial strain distribution of a disc specimen under equi-biaxial loading at $P=1240 \mathrm{~N}$

Figure 7 - Evolution of the crack propagation in a graphite rectangular specimen (U10) under uniaxial loading, maximum principal strain of an approximately $100 \times 100 \mathrm{~mm}^{2}$ window: Maps obtained at the following bending stresses, with maximum observed crack surface length, a) $\sigma_{b}=27.20 \mathrm{MPa}, 2 c=4.72 \mathrm{~mm}$, b) $\sigma_{b}=27.70 \mathrm{MPa}, 2 c=5.30 \mathrm{~mm}$, c) $\left.\sigma_{b}=27.90 \mathrm{MPa}, 2 c=5.50 \mathrm{~mm}, \mathrm{~d}\right) \sigma_{b}=28.05 \mathrm{MPa}, 2 c=5.88 \mathrm{~mm}$, e) $\sigma_{b}=28.30 \mathrm{MPa}$, $2 c=8.30 \mathrm{~mm}, \mathrm{f}) \sigma_{b}=28.40 \mathrm{MPa}, 2 c=10.82 \mathrm{~mm}$

Figure 8- Evolution of the crack propagation in a graphite disk specimen (B04) under equi-biaxial loading, maximum principal strain of an approximately $100 \times 100 \mathrm{~mm}^{2}$ window, a) $\left.\left.\sigma_{b}=11.60 \mathrm{MPa}, 2 c=1.5 \mathrm{~mm}, \mathrm{~b}\right) \sigma_{b}=22.80 \mathrm{MPa}, 2 c=3.5 \mathrm{~mm}, \mathrm{c}\right) \sigma_{b}=22.90$ 
$\mathrm{MPa}, 2 c=10.0 \mathrm{~mm}, \mathrm{~d}) \sigma_{b}=23.00 \mathrm{MPa}, 2 c=13.7 \mathrm{~mm}$, e) $\sigma_{b}=23.05 \mathrm{MPa}, 2 c=16.3 \mathrm{~mm}$, f) $\sigma_{b}=23.10 \mathrm{MPa}, 2 c=16.9 \mathrm{~mm}$

Figure 9 - Crack length evolution of uniaxially and equi-biaxially loaded specimens. Specimen codes are identified in the legend.

Figure 10- Crack opening ratio $(r)$ (a) sensitivity to crack depth $(c=5 \mathrm{~mm})$ b) sensitivity to crack length ( $a=1 \mathrm{~mm}$ ) (c) as a function of bending stress for uniaxially and equibiaxially loaded specimens for finite element and analytical solutions $(2 c=10 \mathrm{~mm}$ and $a=2 \mathrm{~mm})$

Figure 11- (a) Schematic crack mouth opening displacement calculation method (b) radial displacement perpendicular to the crack (c) Evolution of the crack mouth opening displacement of uniaxially and equi-biaxially loaded specimens

Figure 12 - Crack opening ratio of a semi-elliptical crack $(2 \mathrm{c}=10 \mathrm{~mm}$ and a $=2 \mathrm{~mm})$ under uniaxial and biaxial loading, theory, elastic FE and microcracking FE 
Figure 1(a)

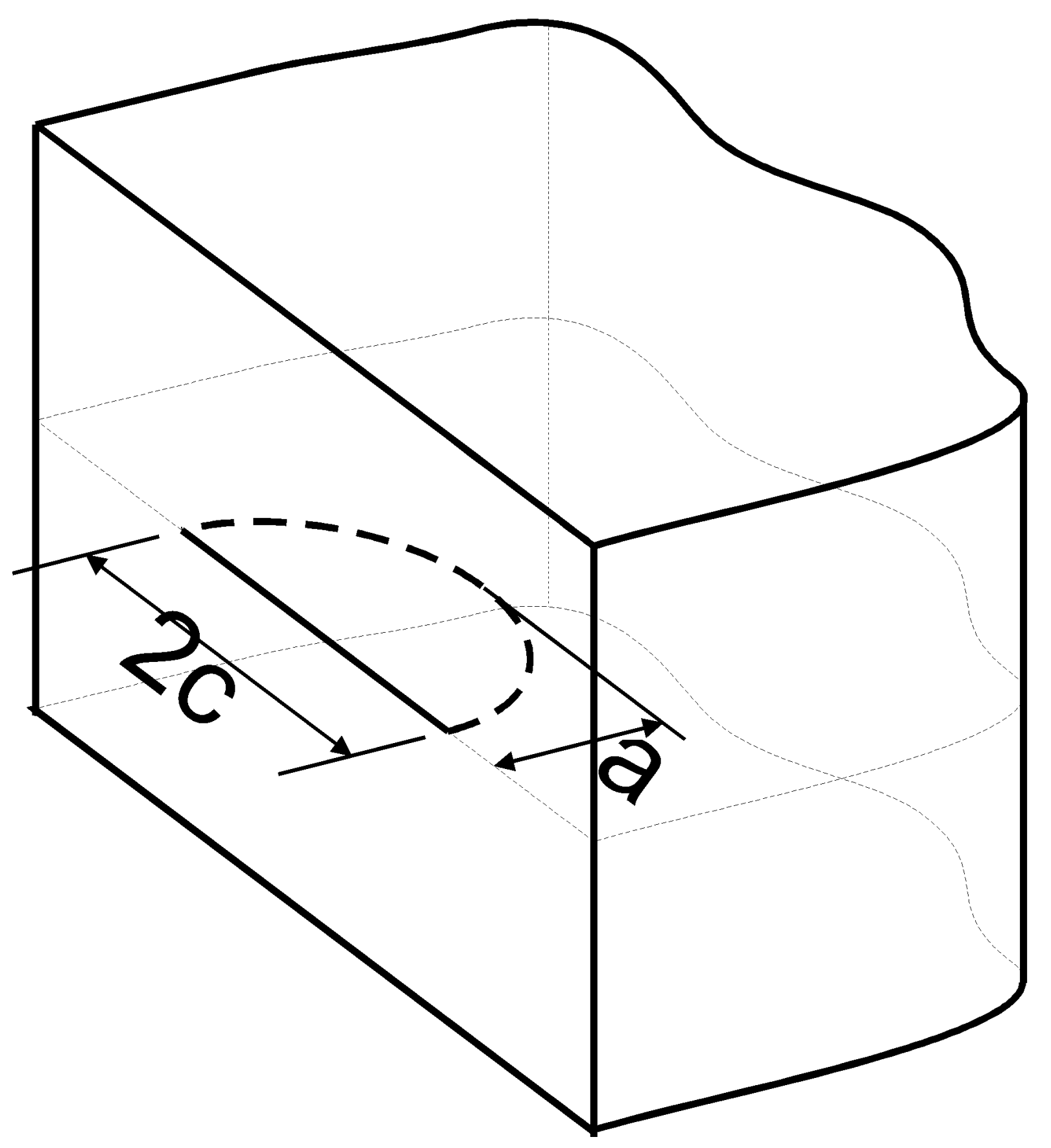




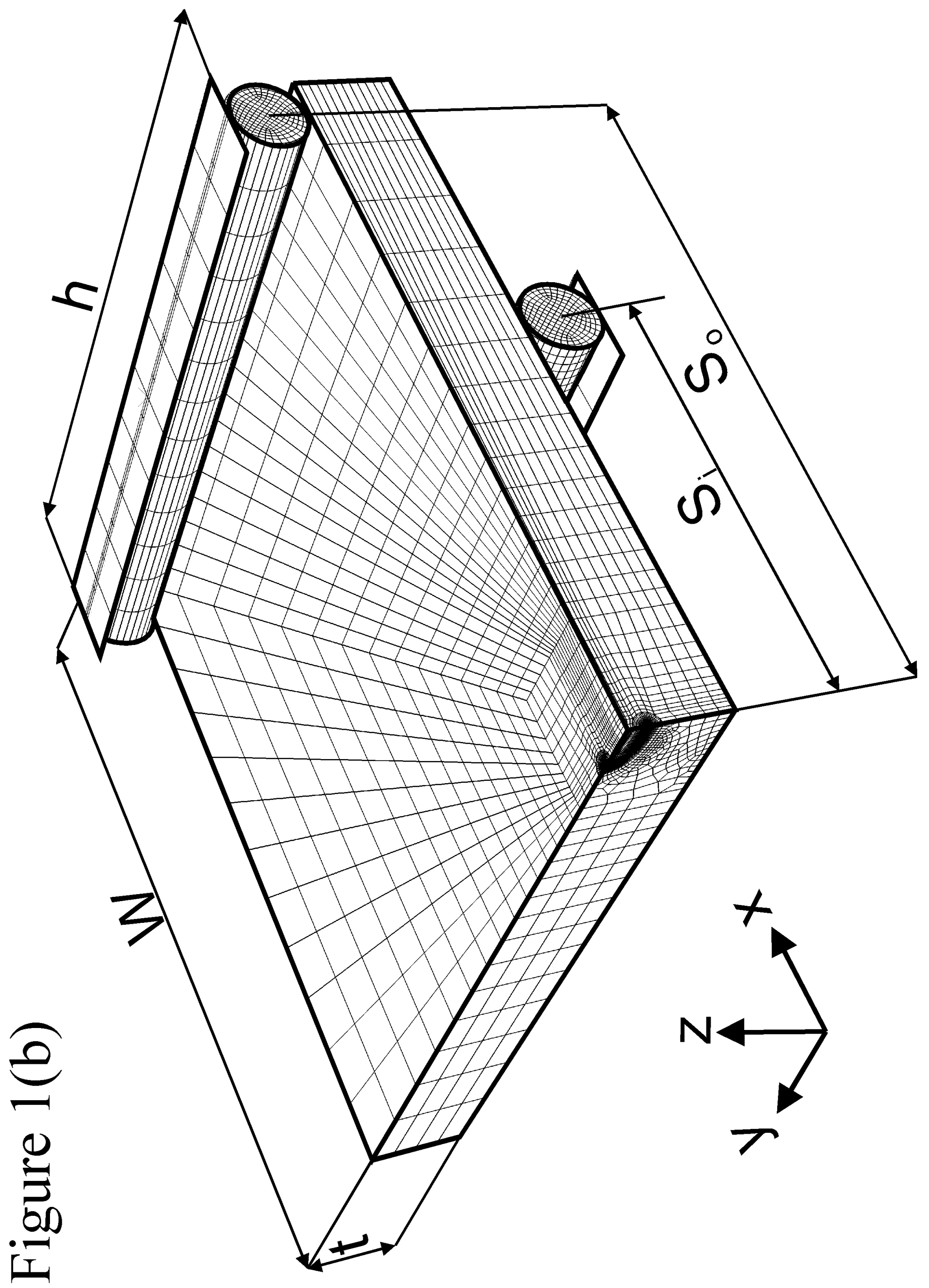




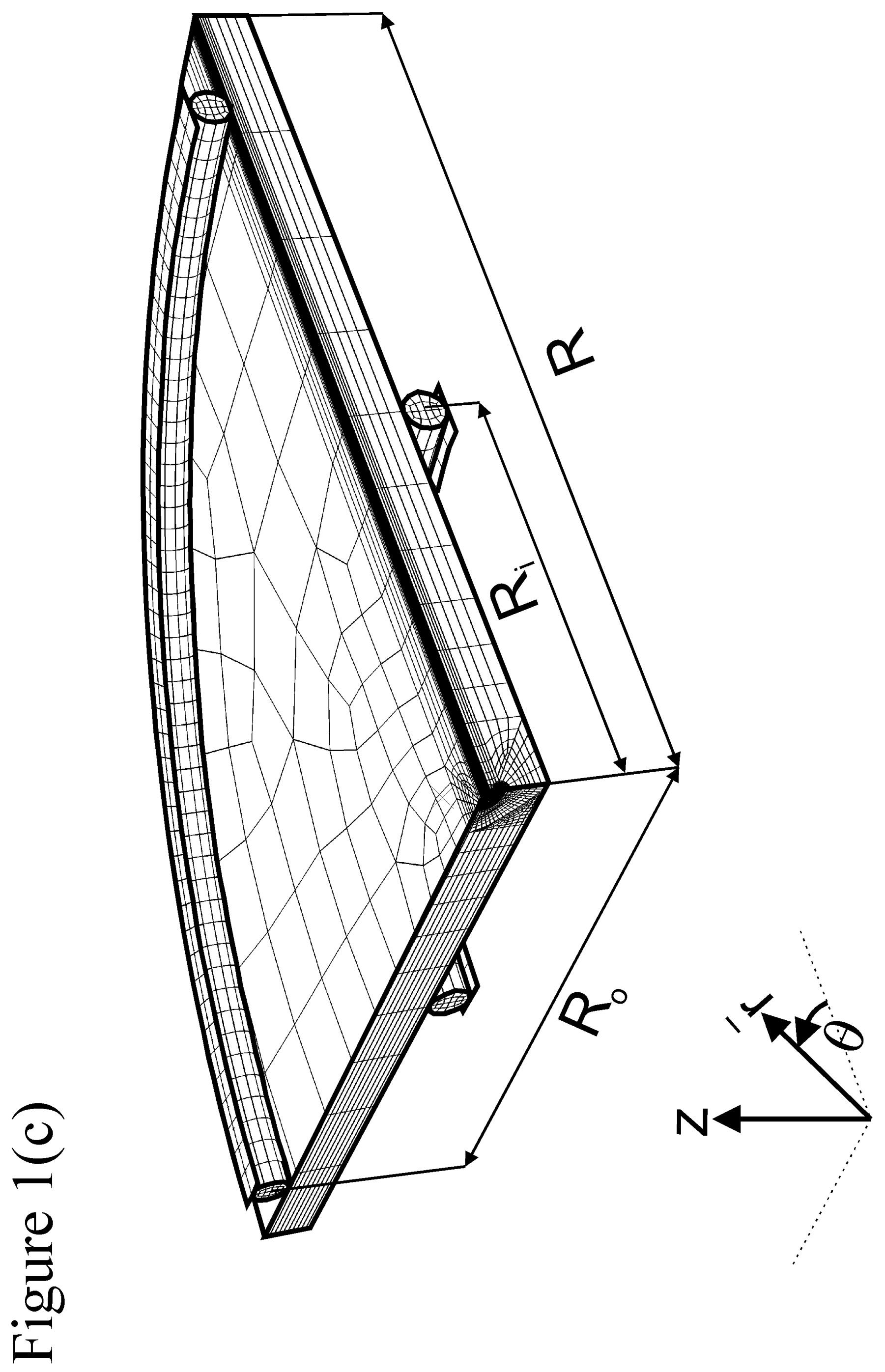




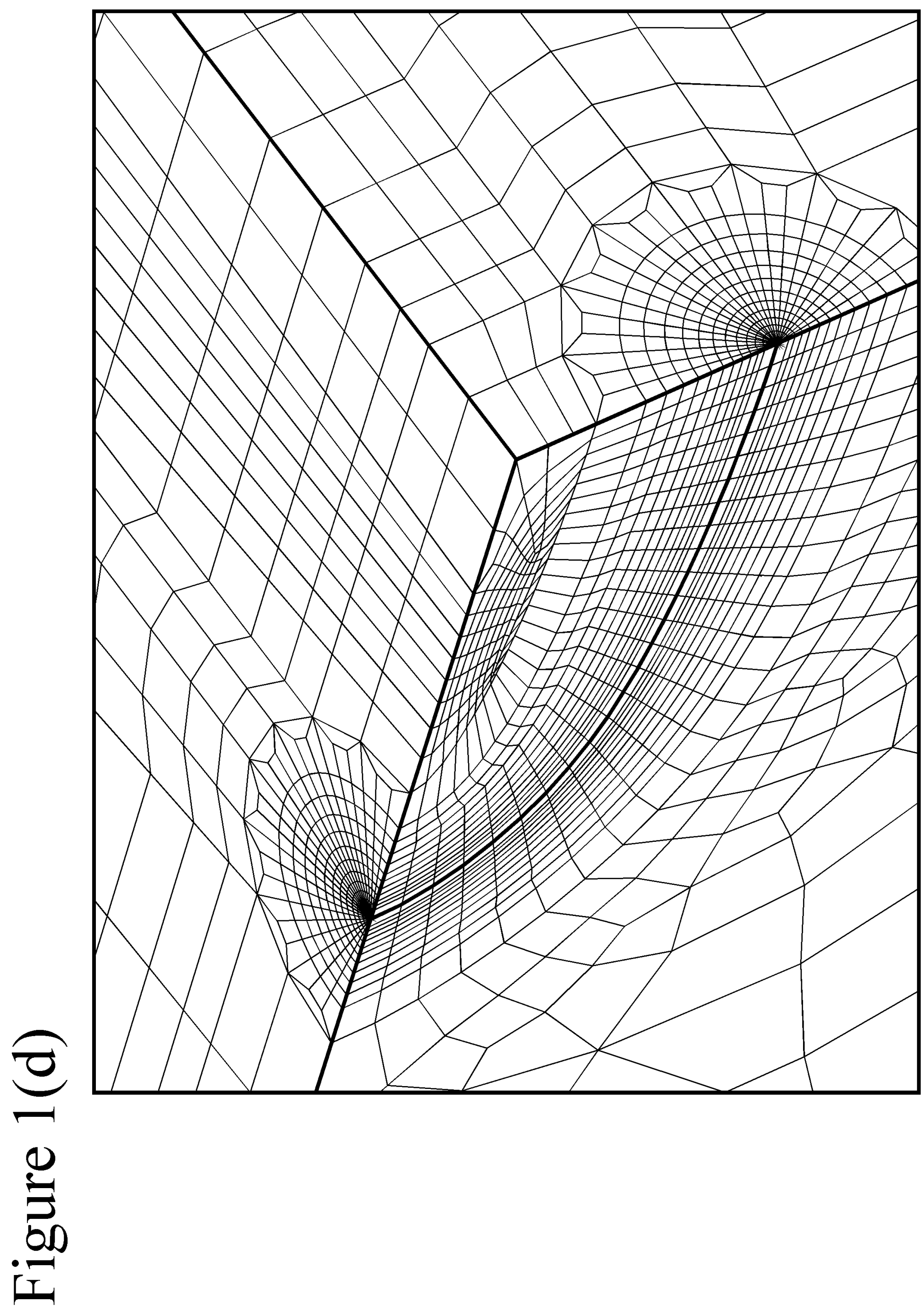


Normalised mode I stress intensity factor, $Y_{I} \stackrel{\overbrace{0}^{\circ}}{\circ}$

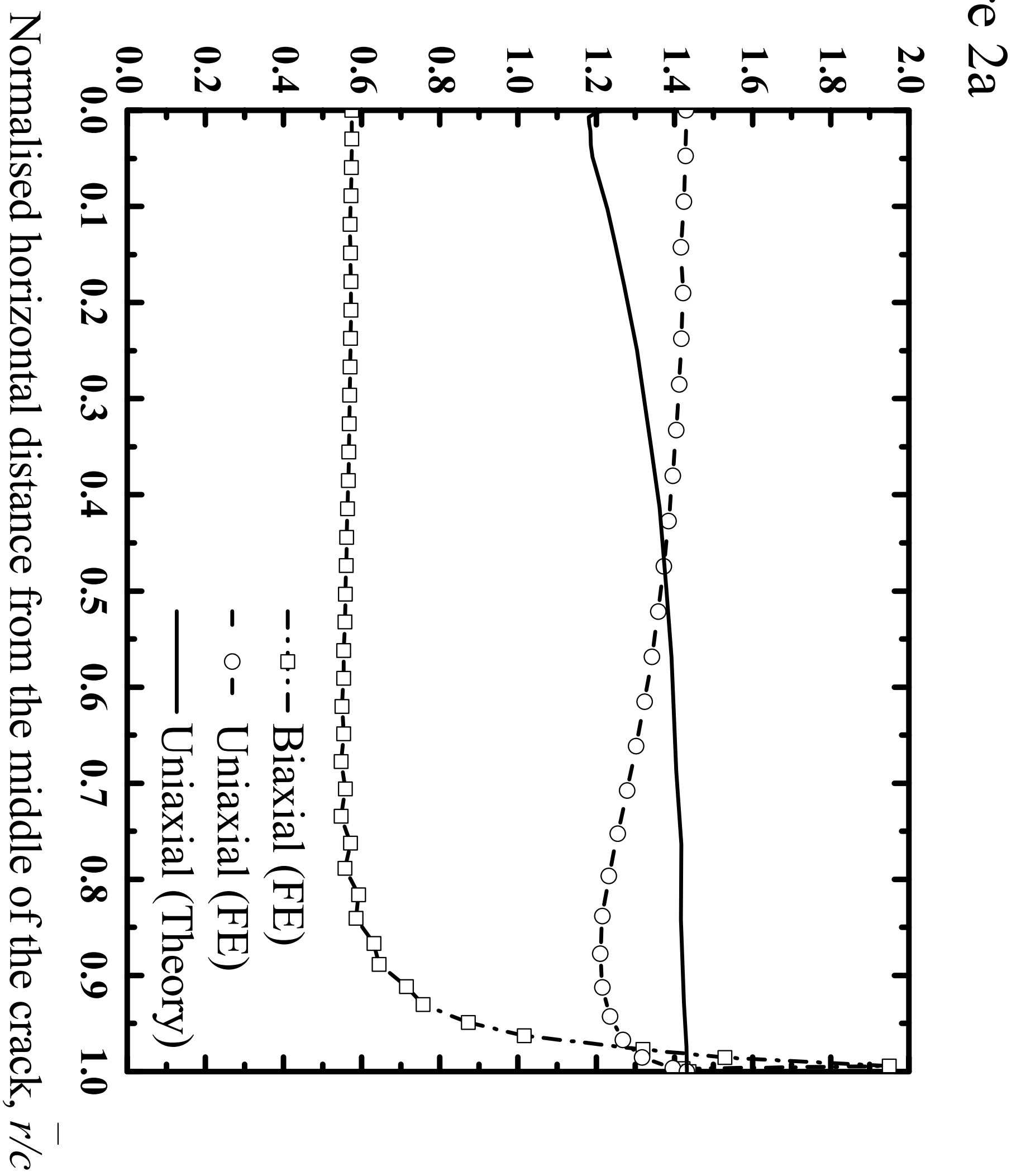


Normalised maximum principal stress, $\sigma_{I} / \sigma_{b}$

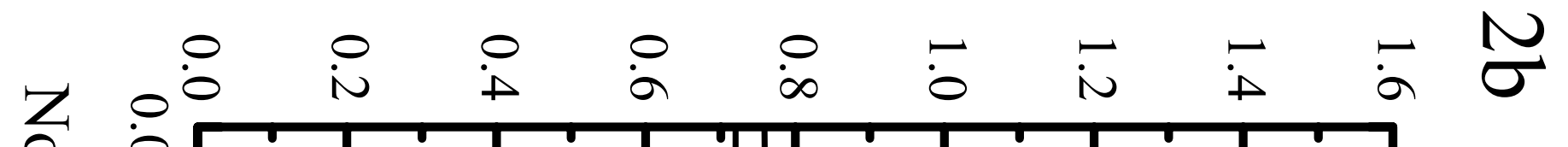

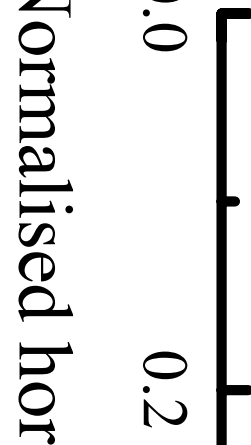

N

$\vec{\sigma}:$

啇

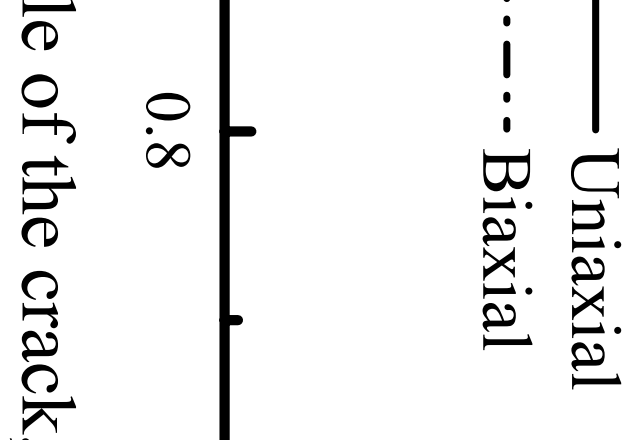

$\pi$

ì 
Figure 3a

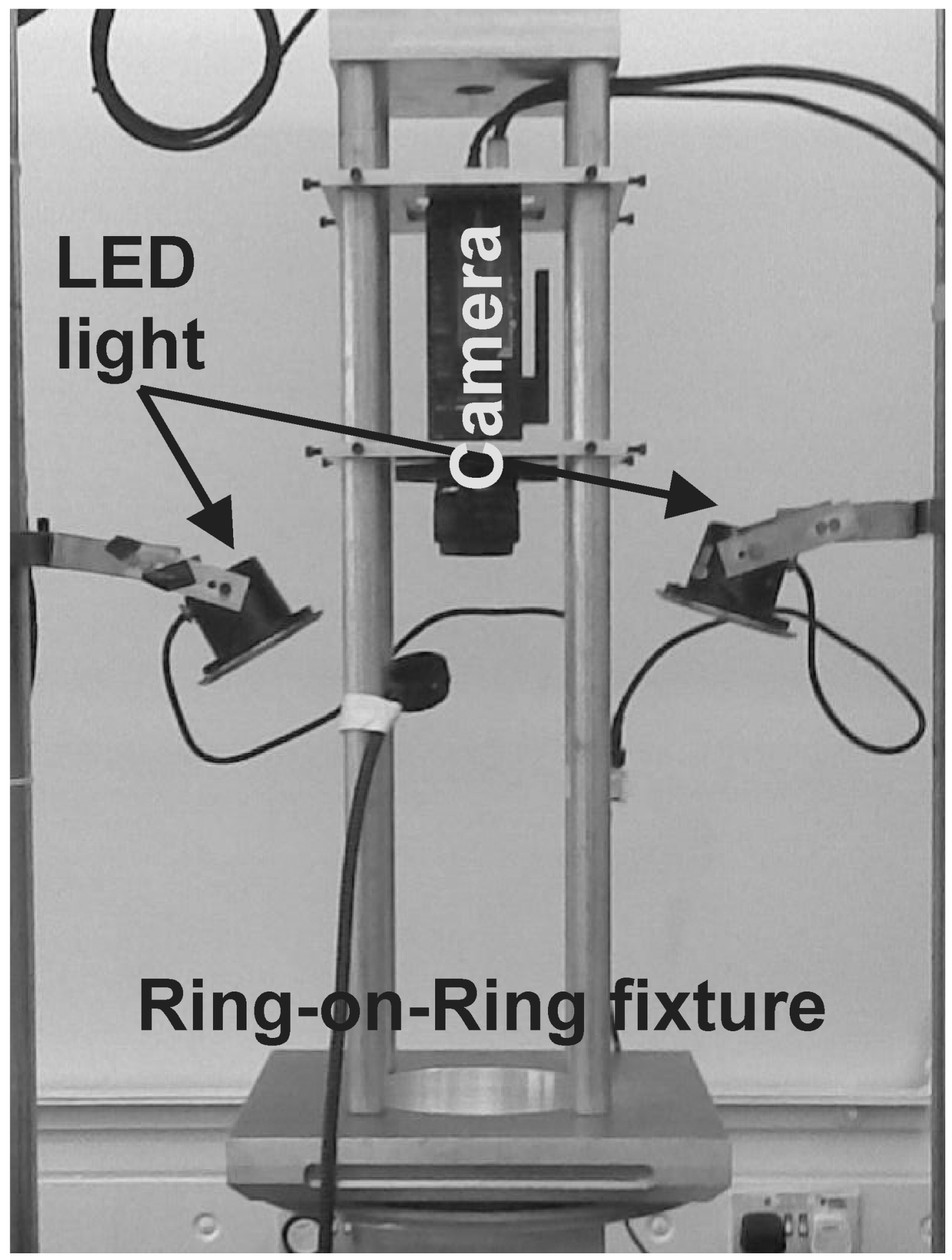


Figure $3 b$

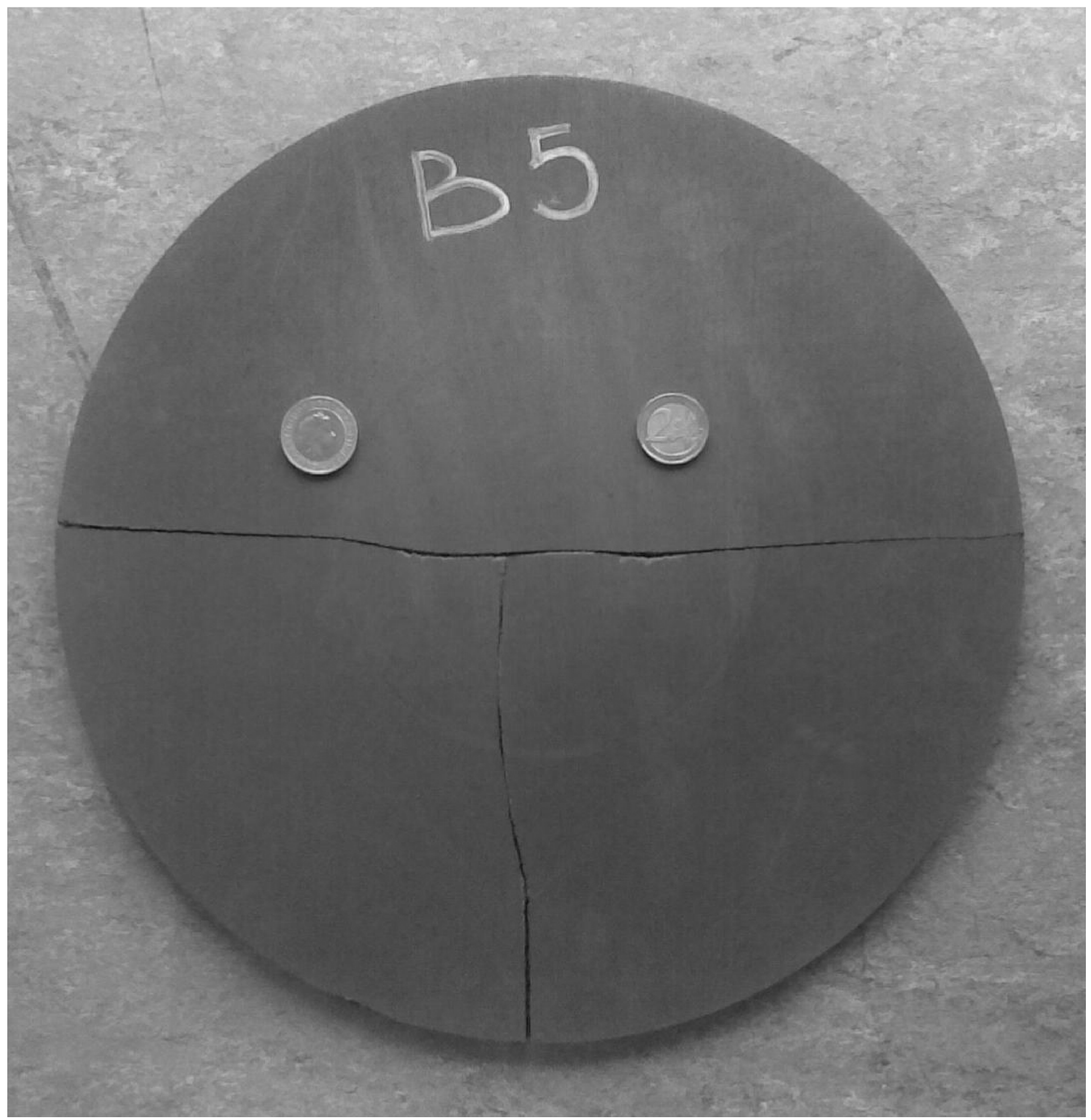




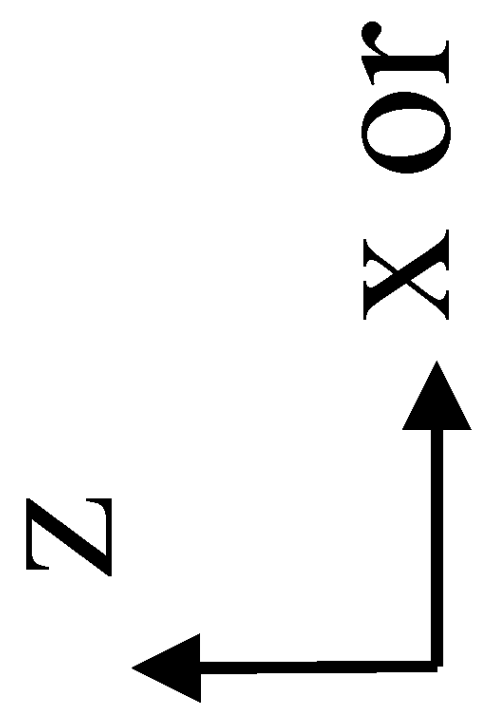

0

(1)

id

bo

T

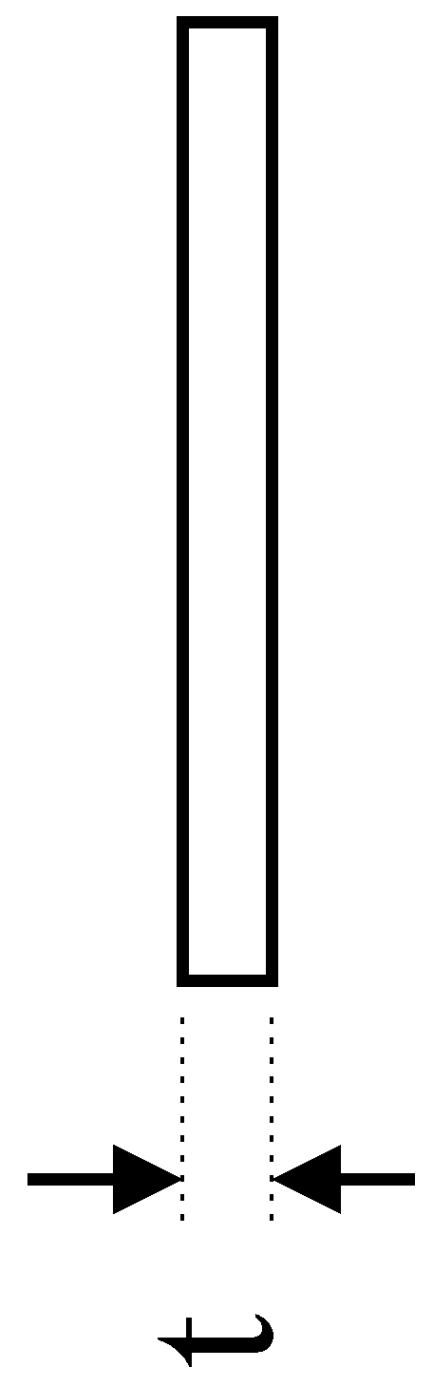




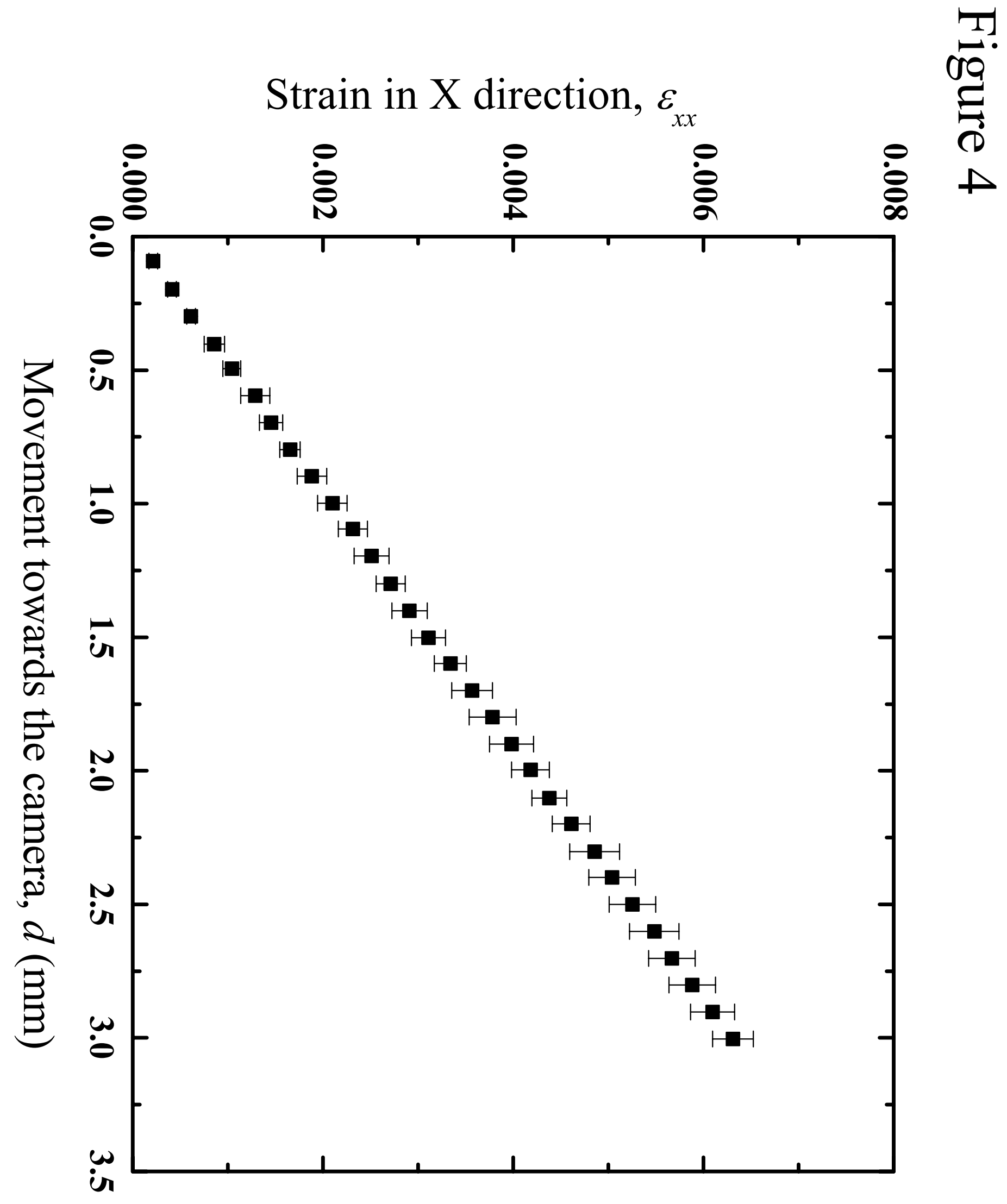




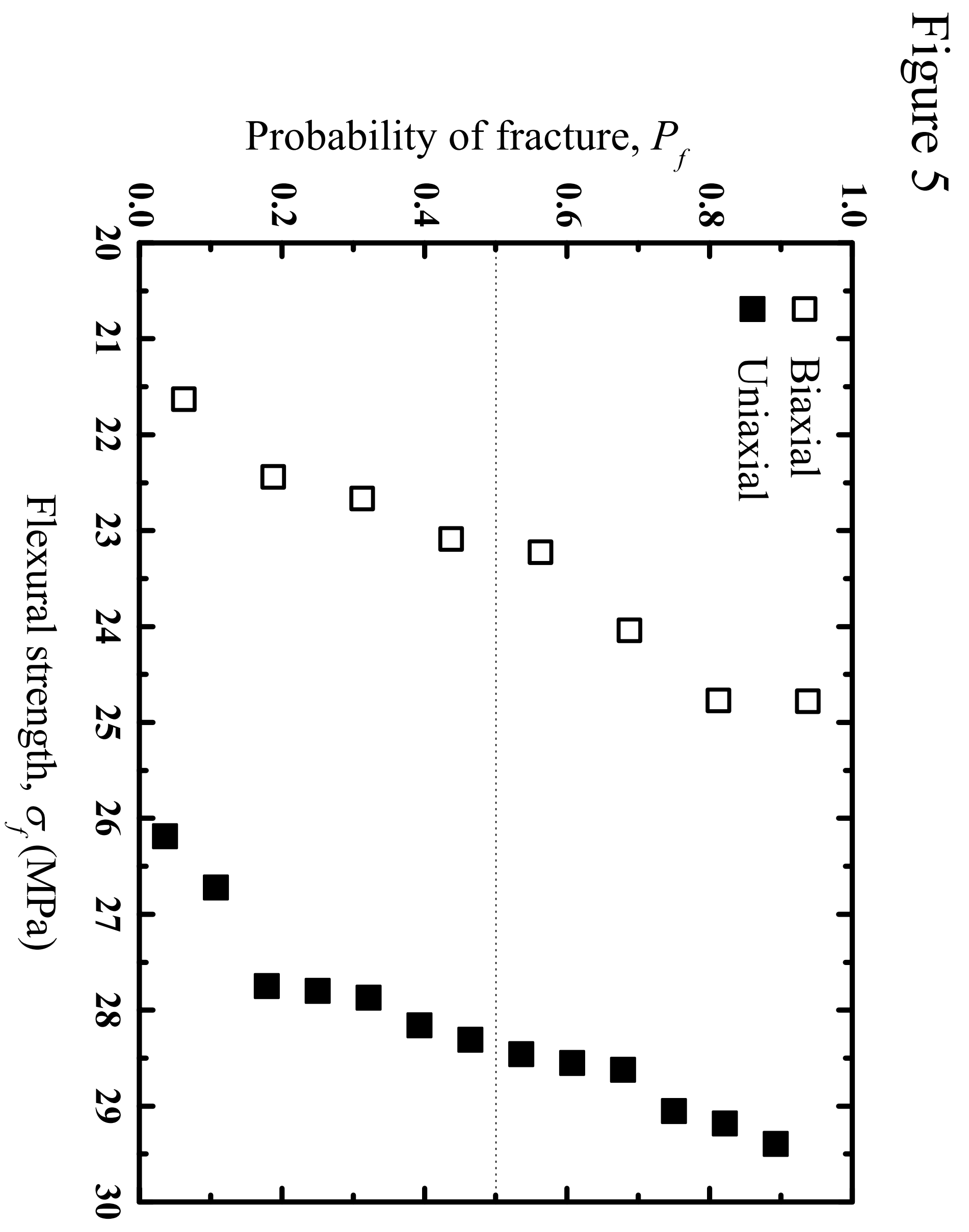




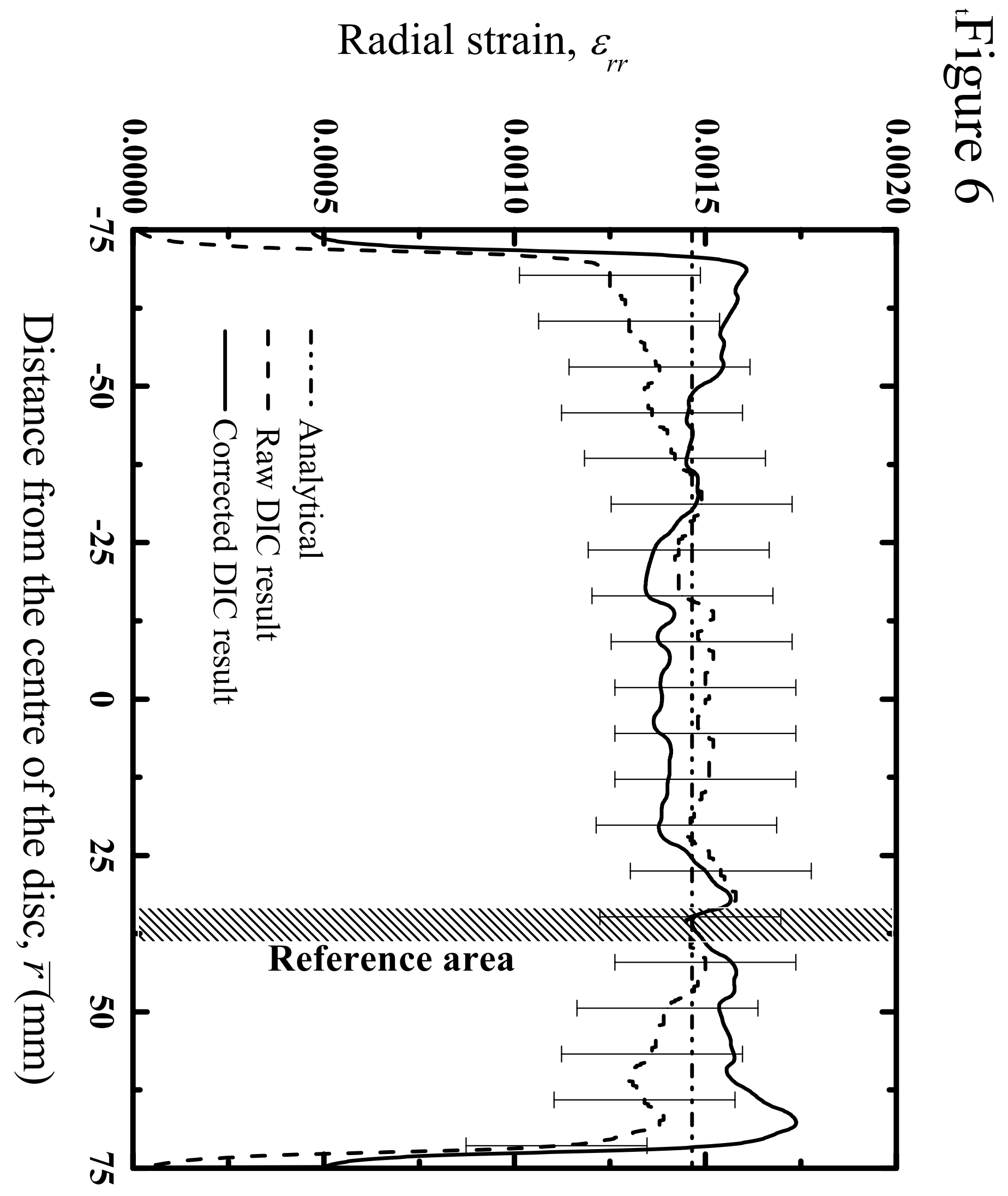




\section{UIE.IT [PUIOU UnU!XeW}

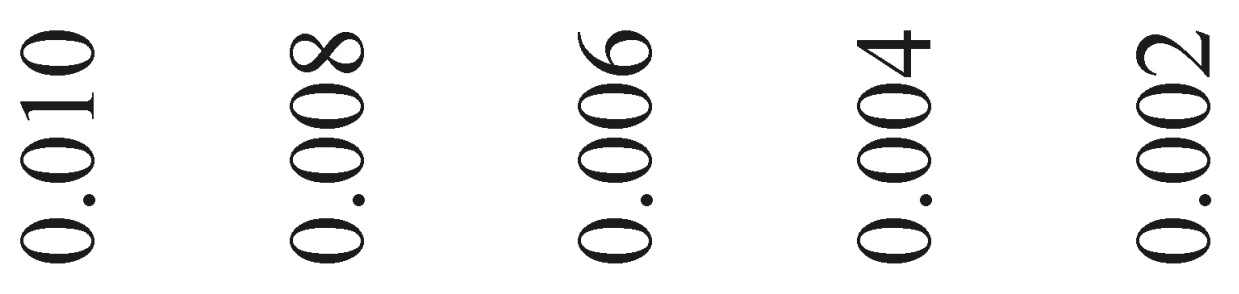

v

$\frac{n}{1}$

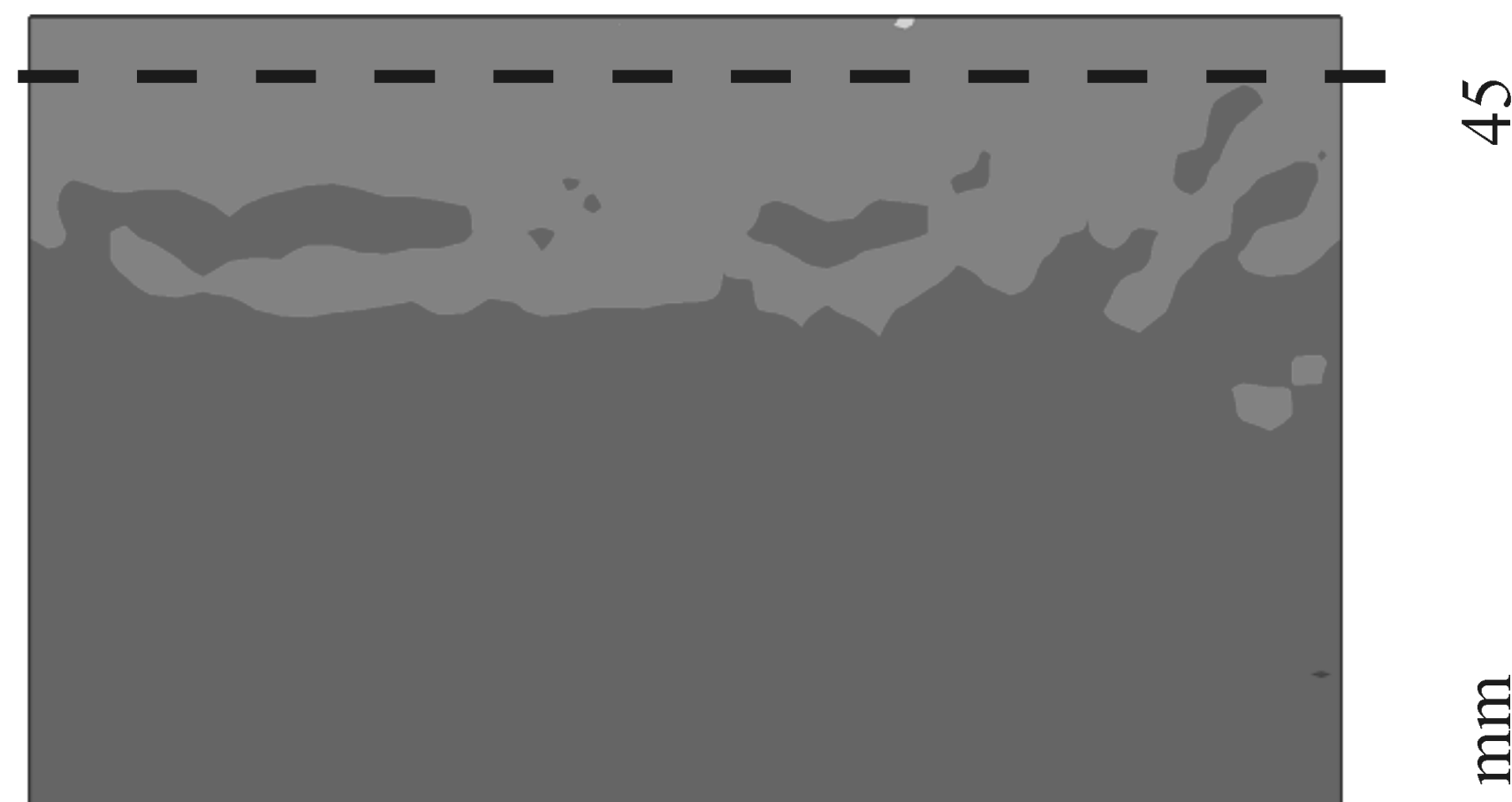

$\nabla$

$N$

(1)

$\Xi$

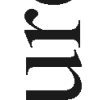

bo

$-7$

I 


\section{UIE.IS [EULOU UINU!XeW}

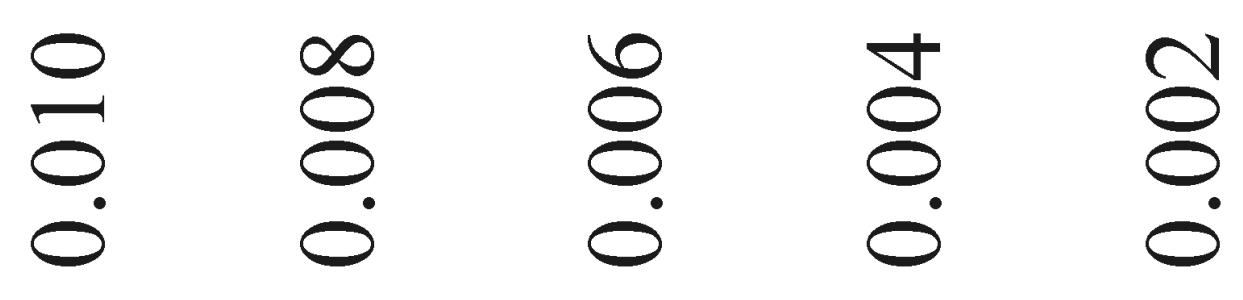

in

守

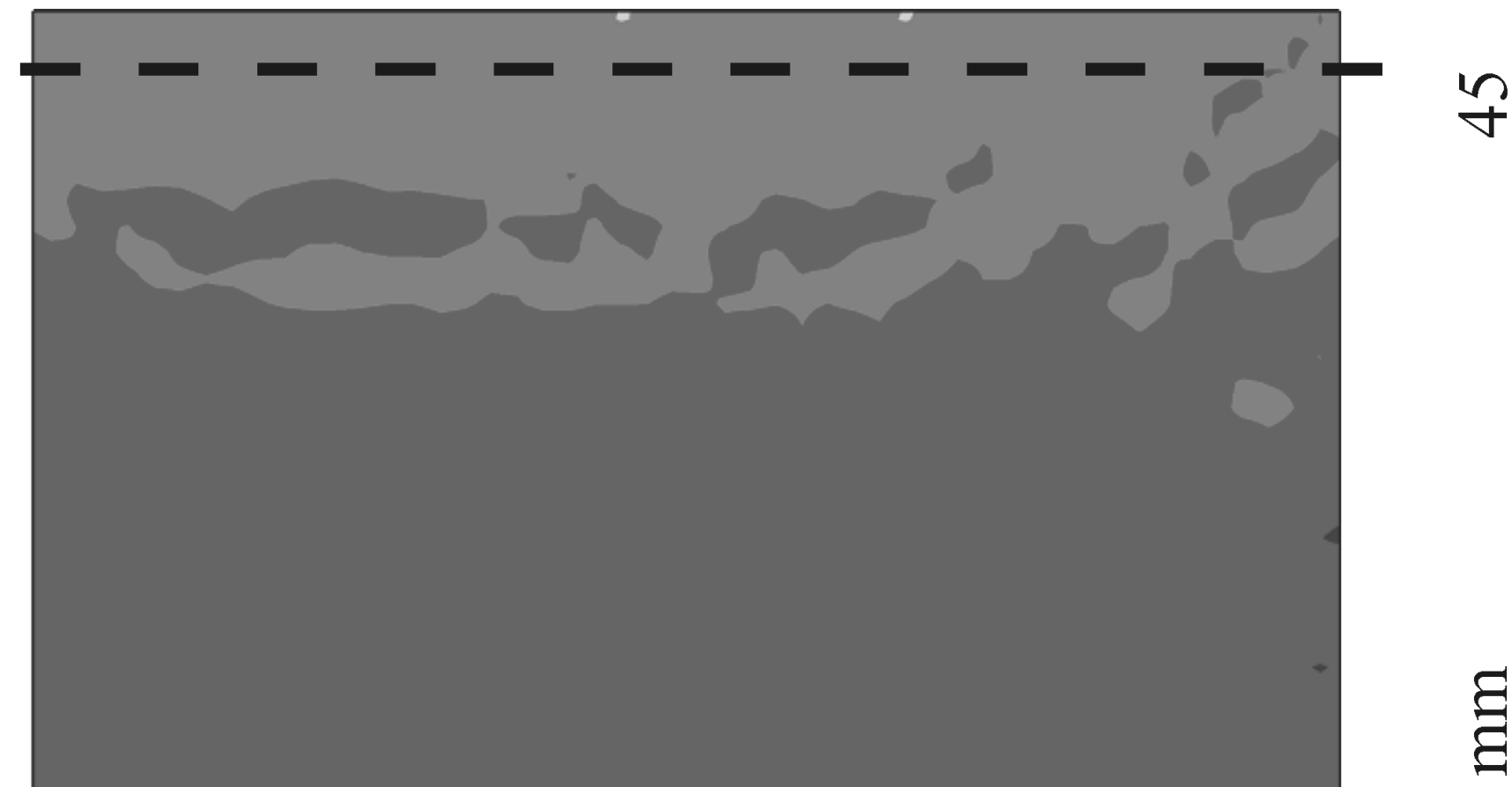

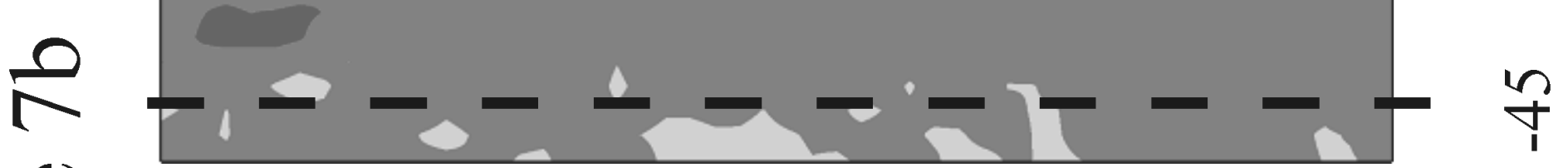

$\underset{b}{3}$

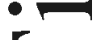

I 


\section{UIE.IS [EULOU UINU!XeW}

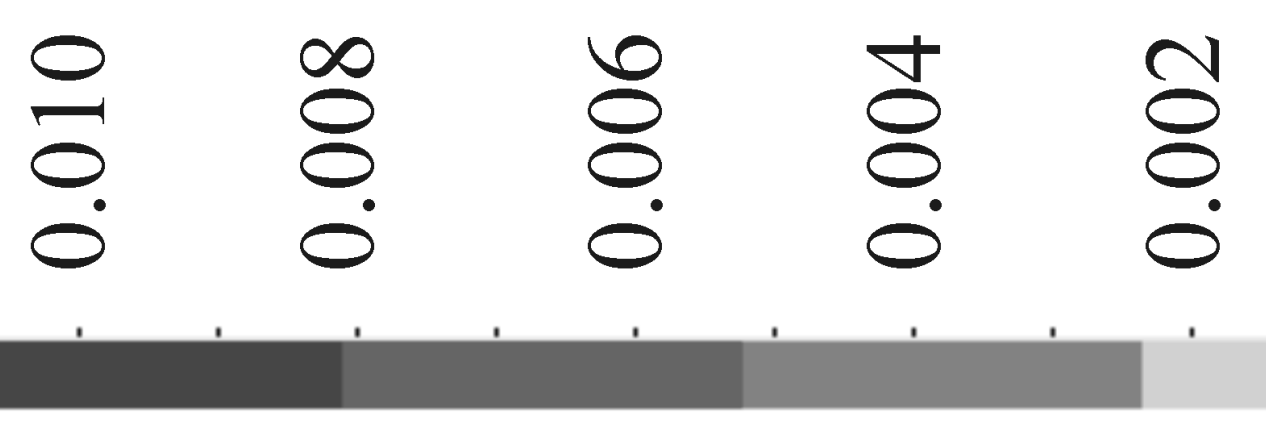

$\stackrel{\sim}{\square}$

i⿱

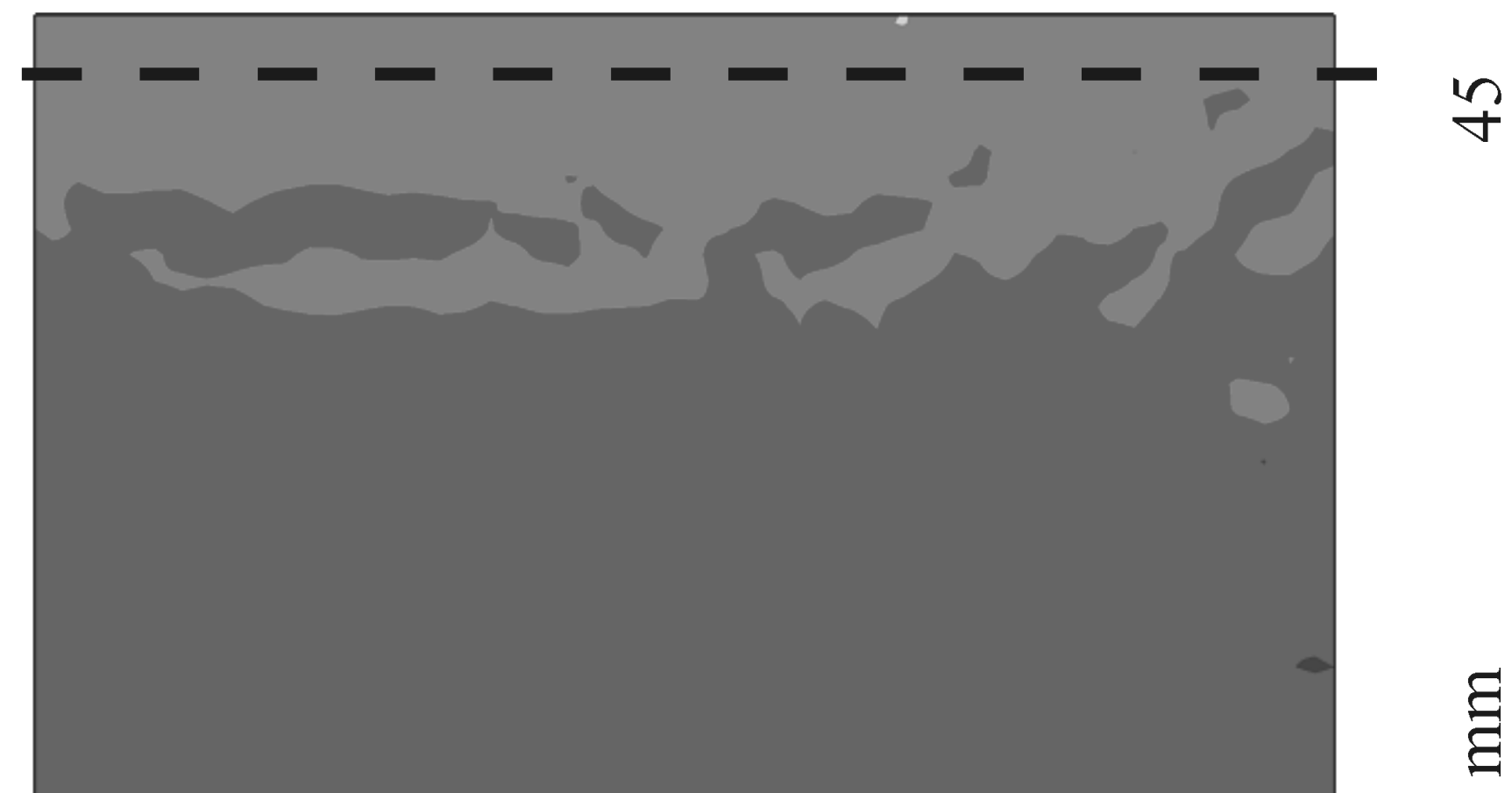

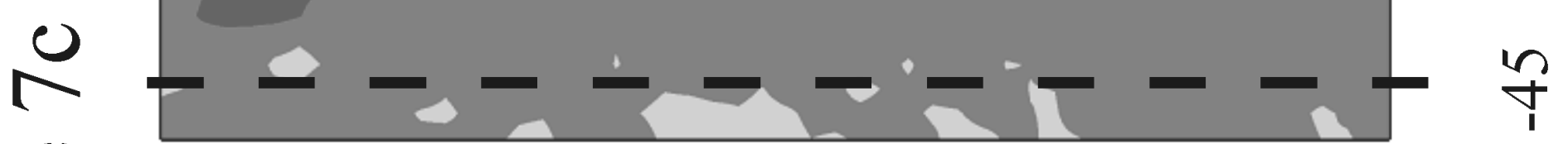

$\frac{1}{60}$

$-$

II 


\section{U!EITS [ЕULOU UnU!XEW}

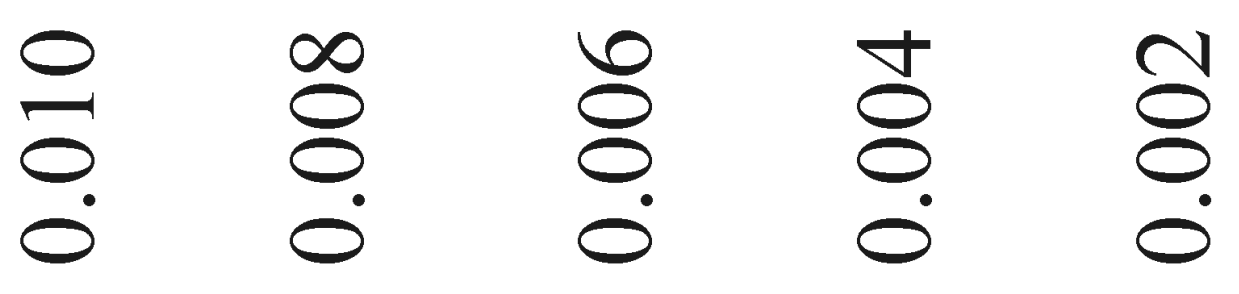

v

v

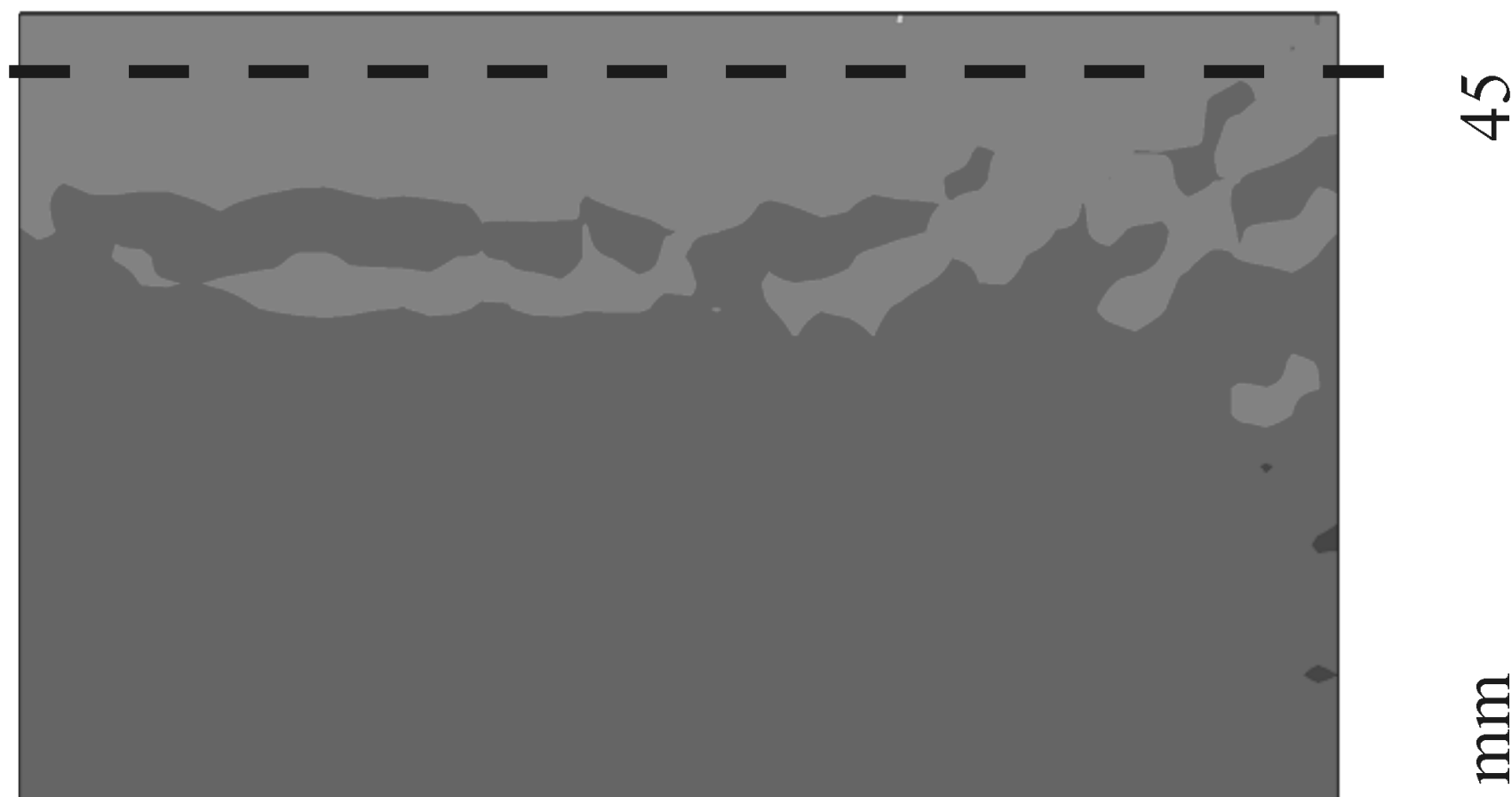

ర

$N$

(1)

$\Xi$

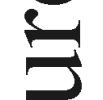

bo

$-\square$

I 


\section{U!EITS [ЕULOU UnU!XEW}

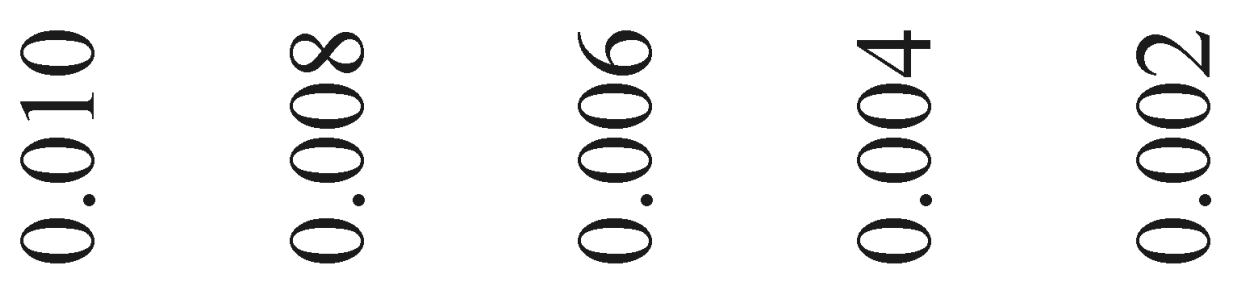

v

v

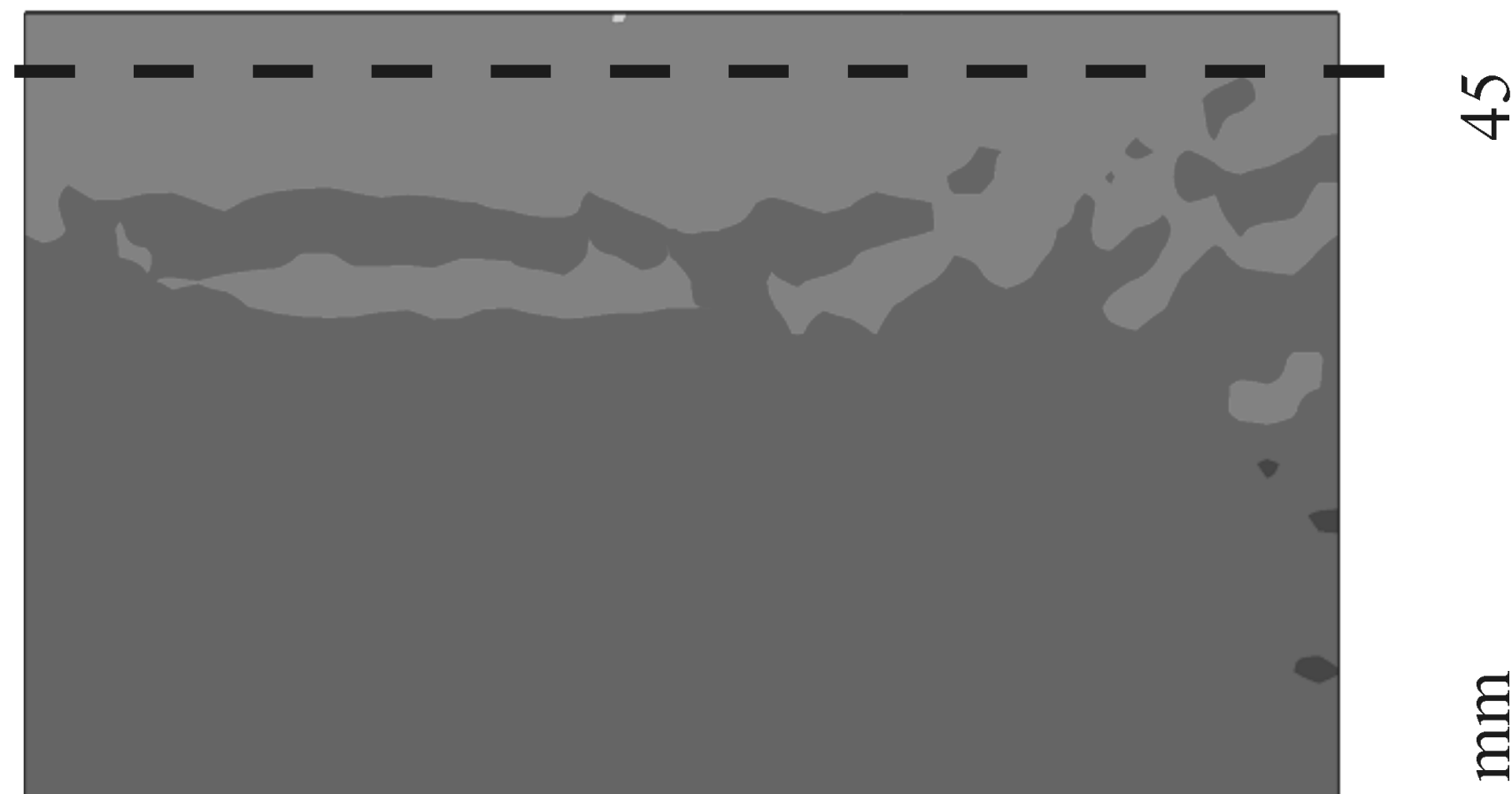

(1)

N

(1)

$\Xi$

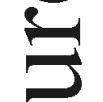

bo

$\cdot-$

I 


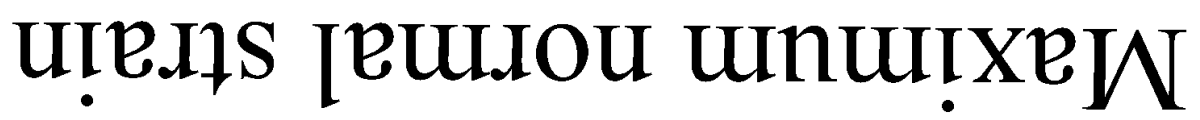
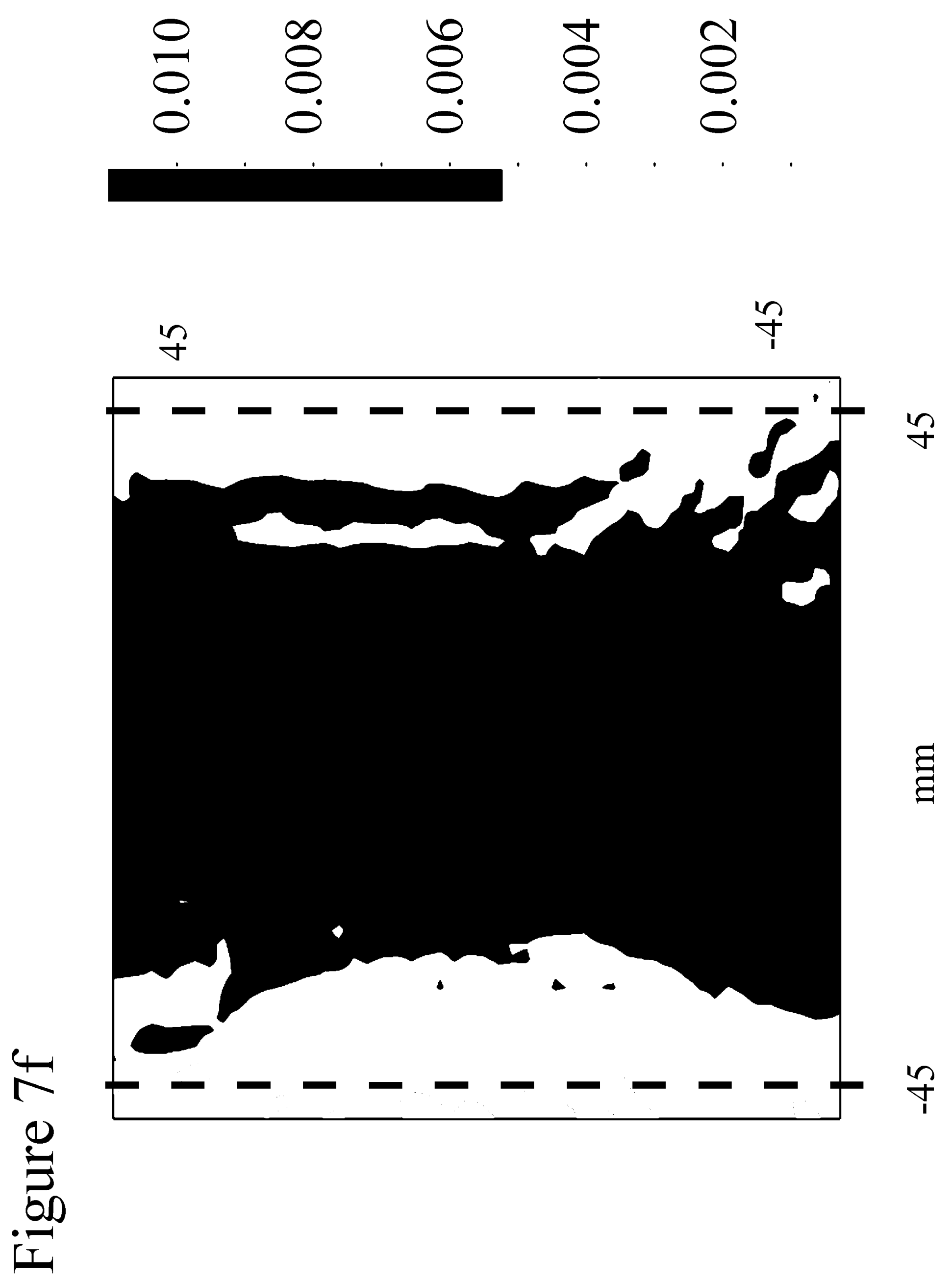


\section{U!PII [EULOU UnU!XEW}
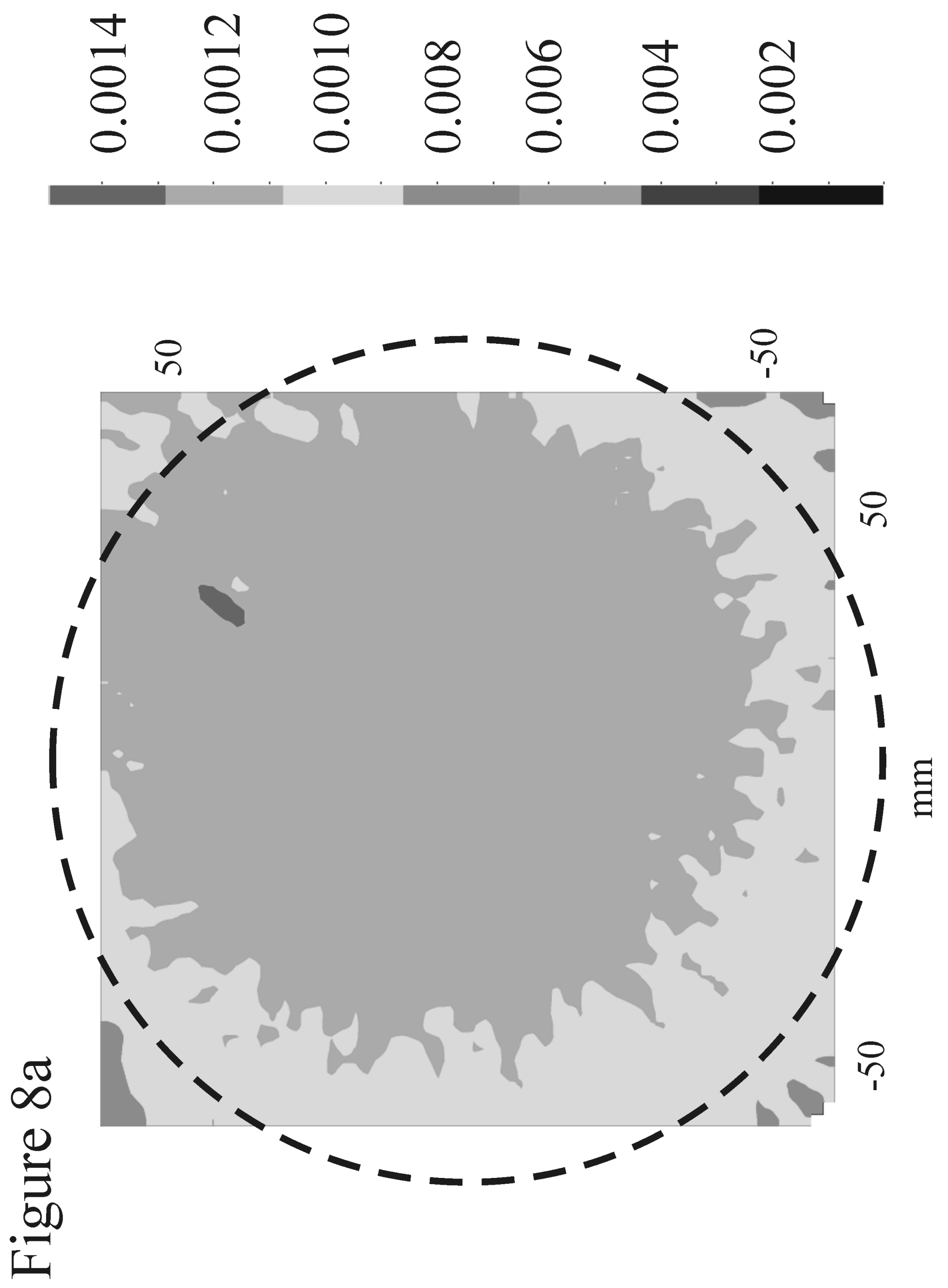


\section{U!PII [EULOU UnU!XEW}
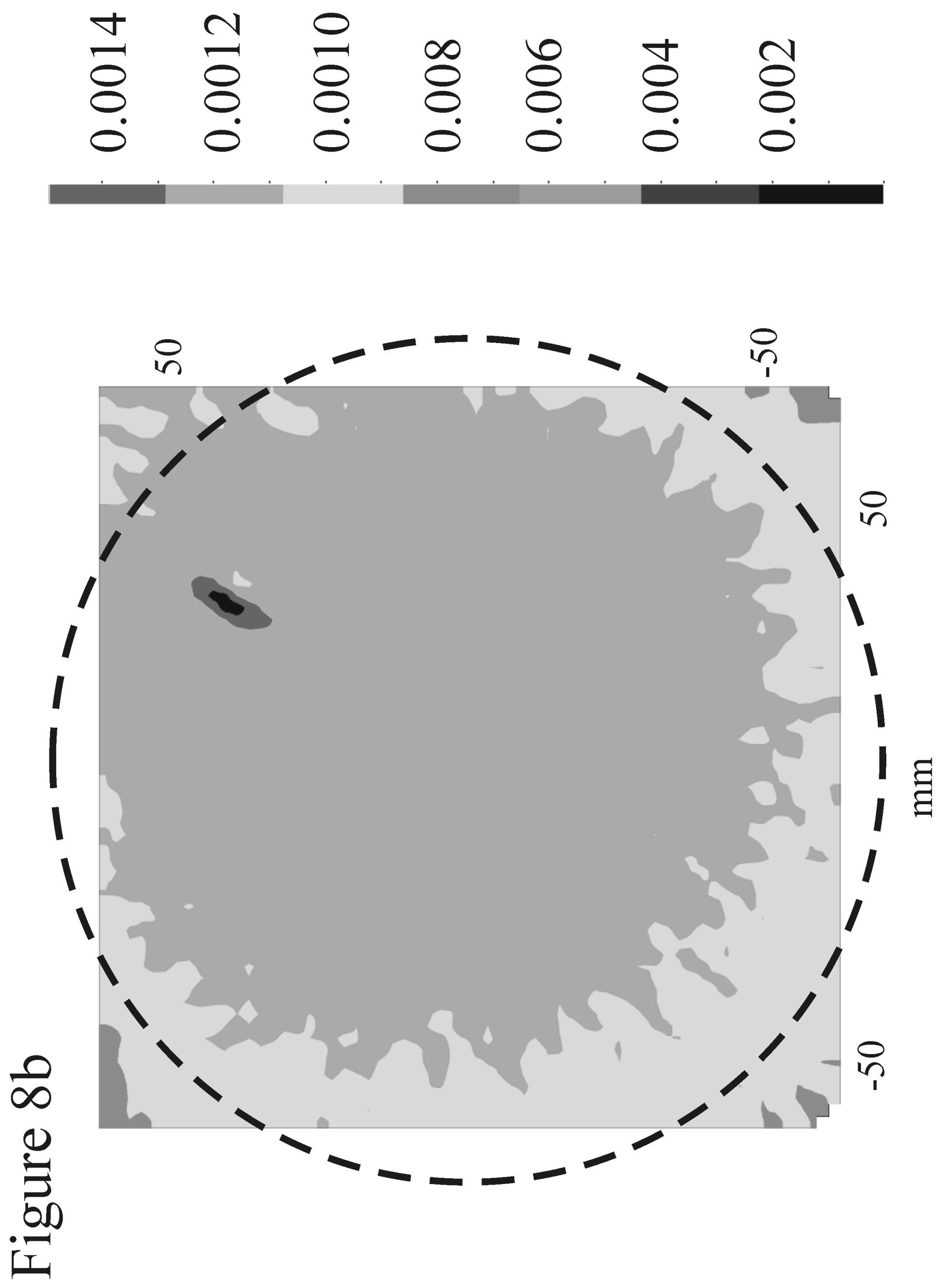


\section{U!PIIS [EULOU UnU!XEW}
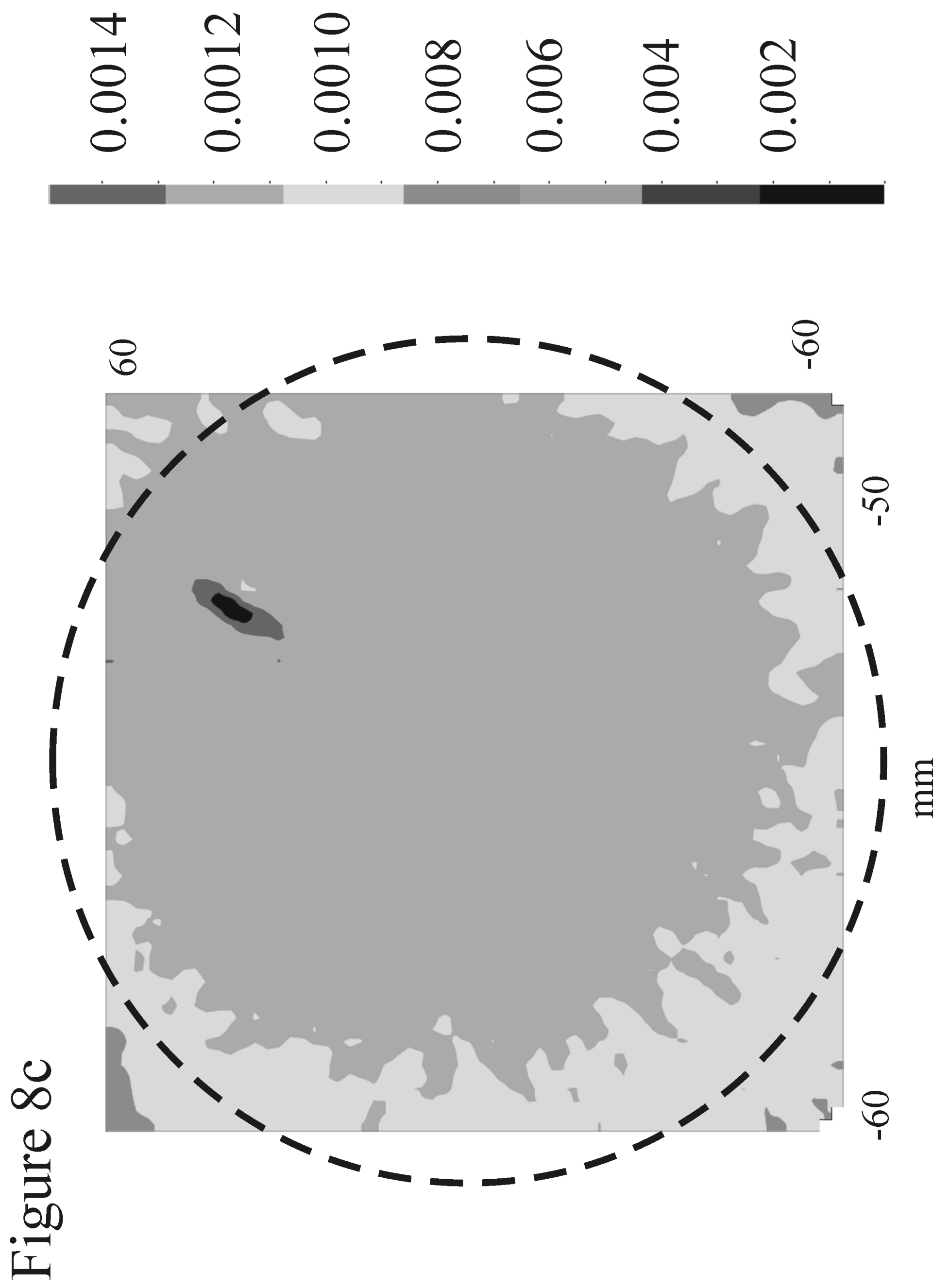


\section{U!PIIS [EULOU UnU!XEW}
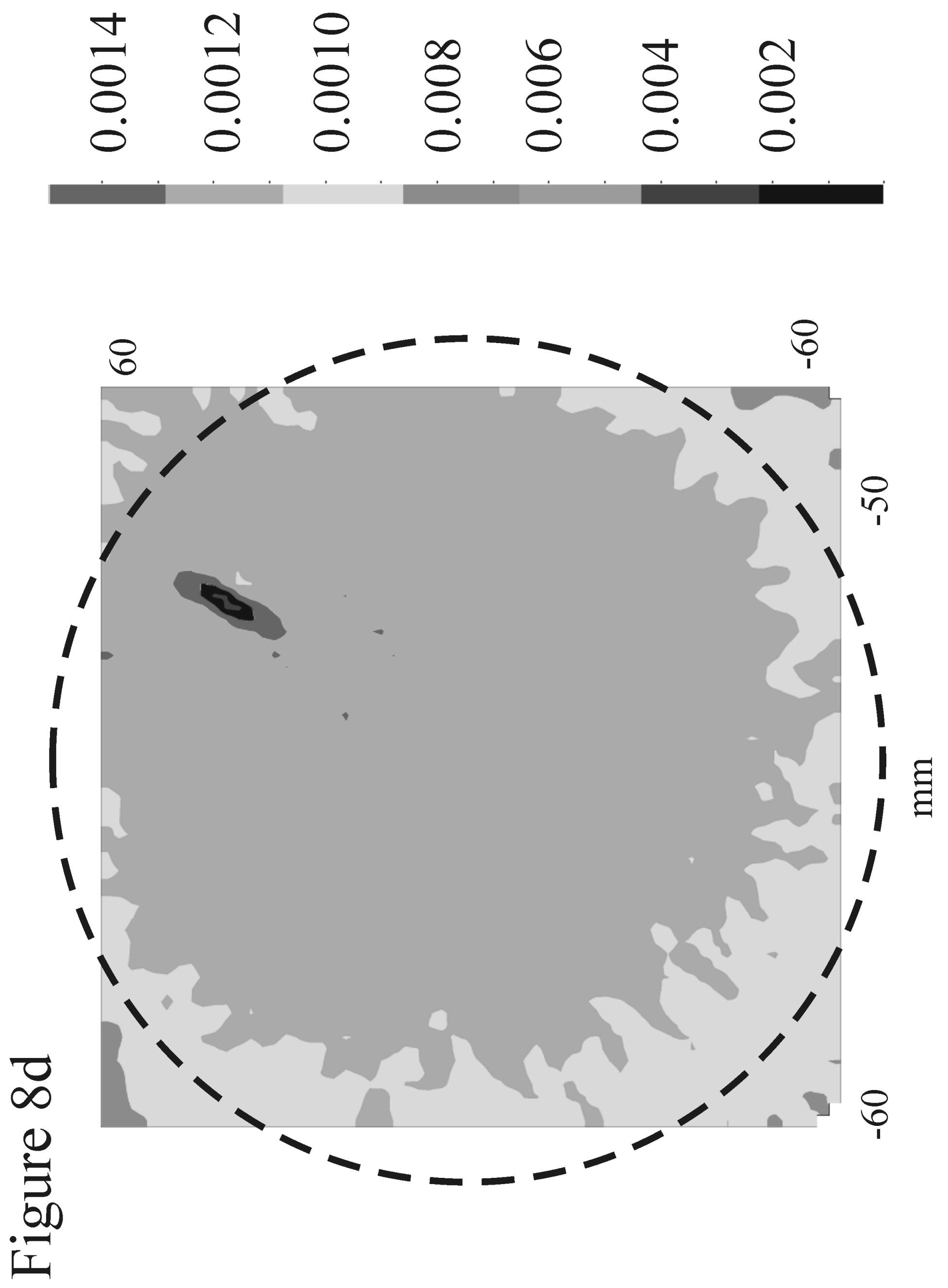


\section{U!PII [EULOU UnU!XEW}
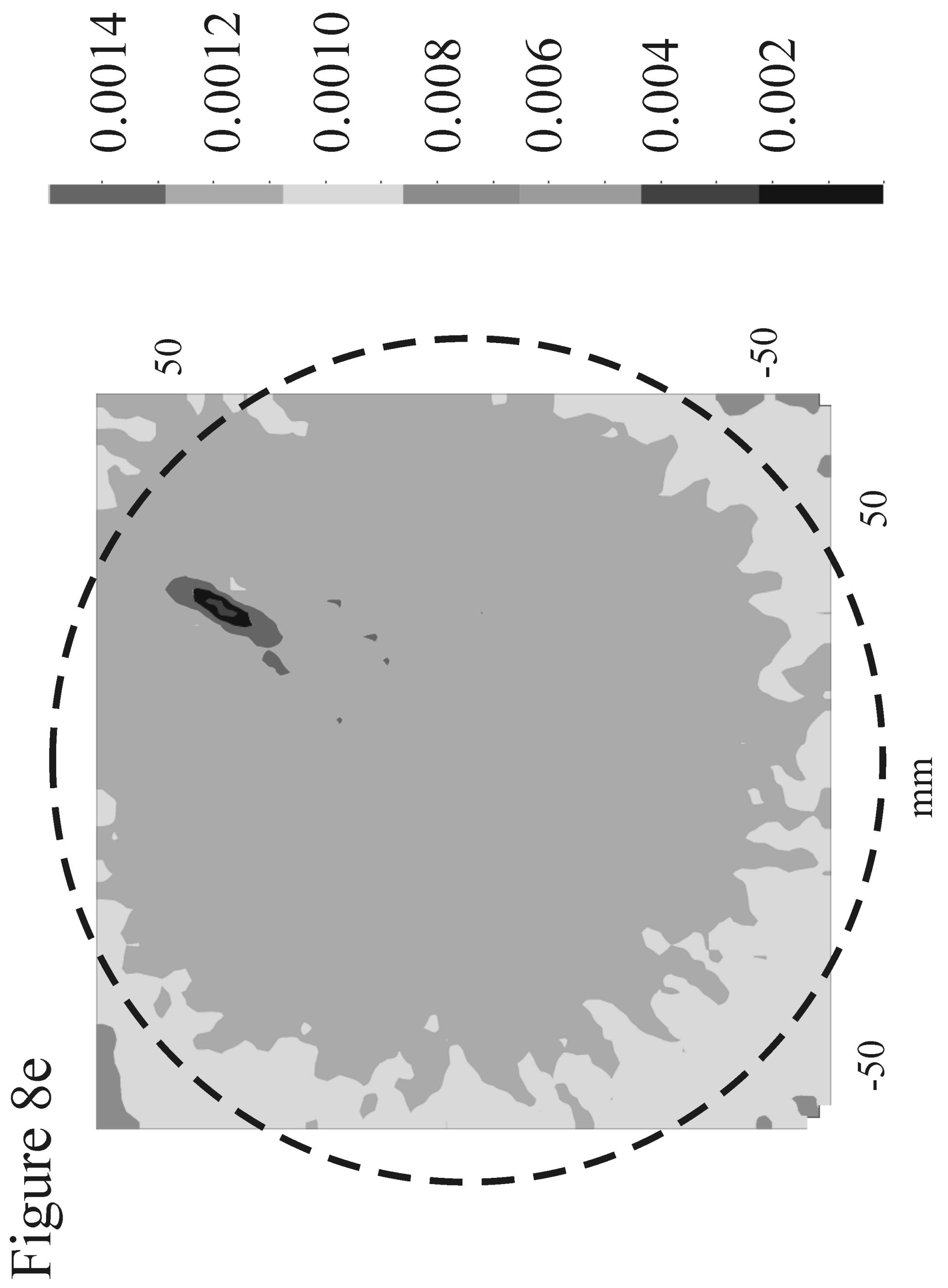


\section{U!PII [EULOU UnU!XEW}
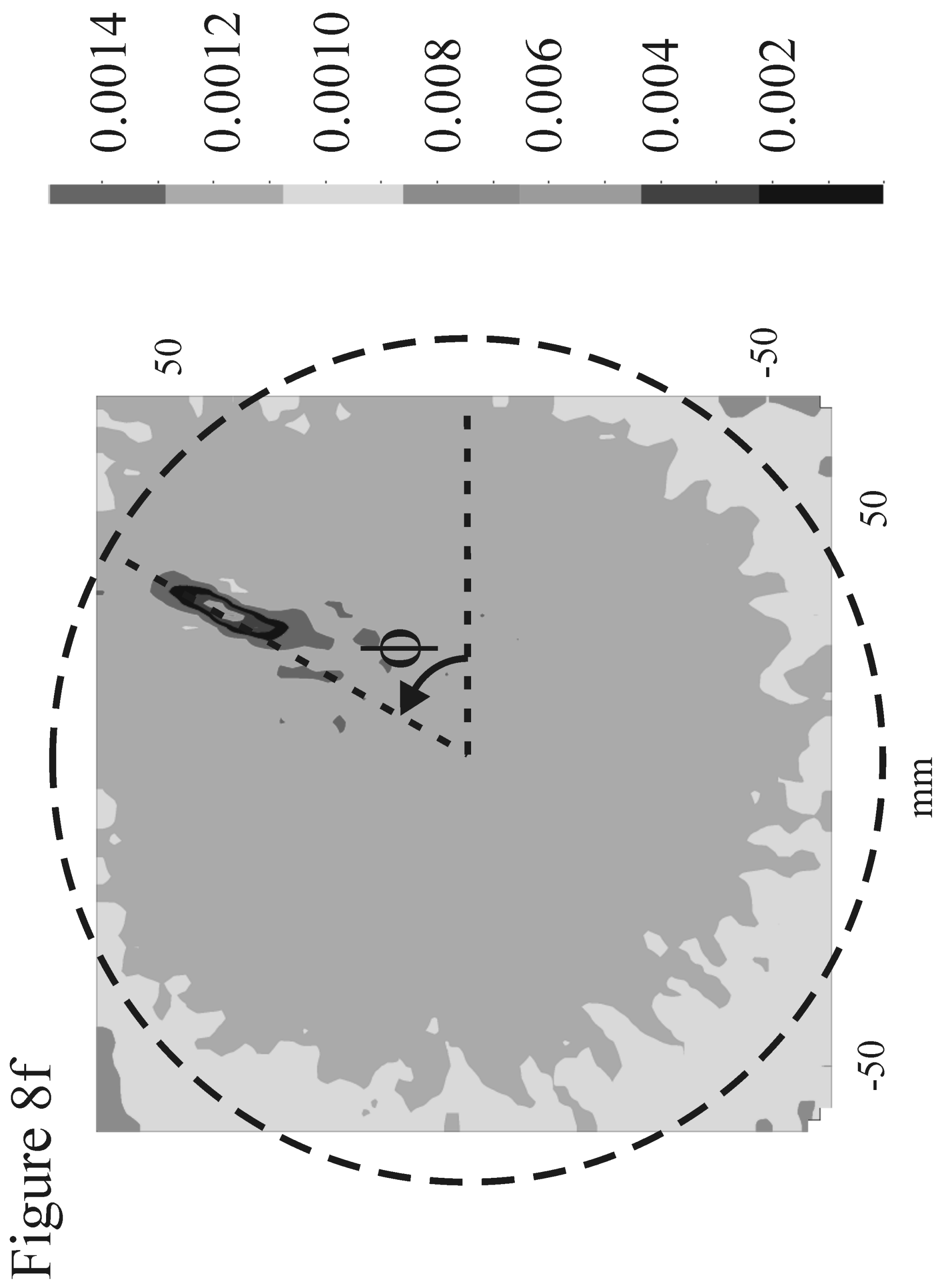


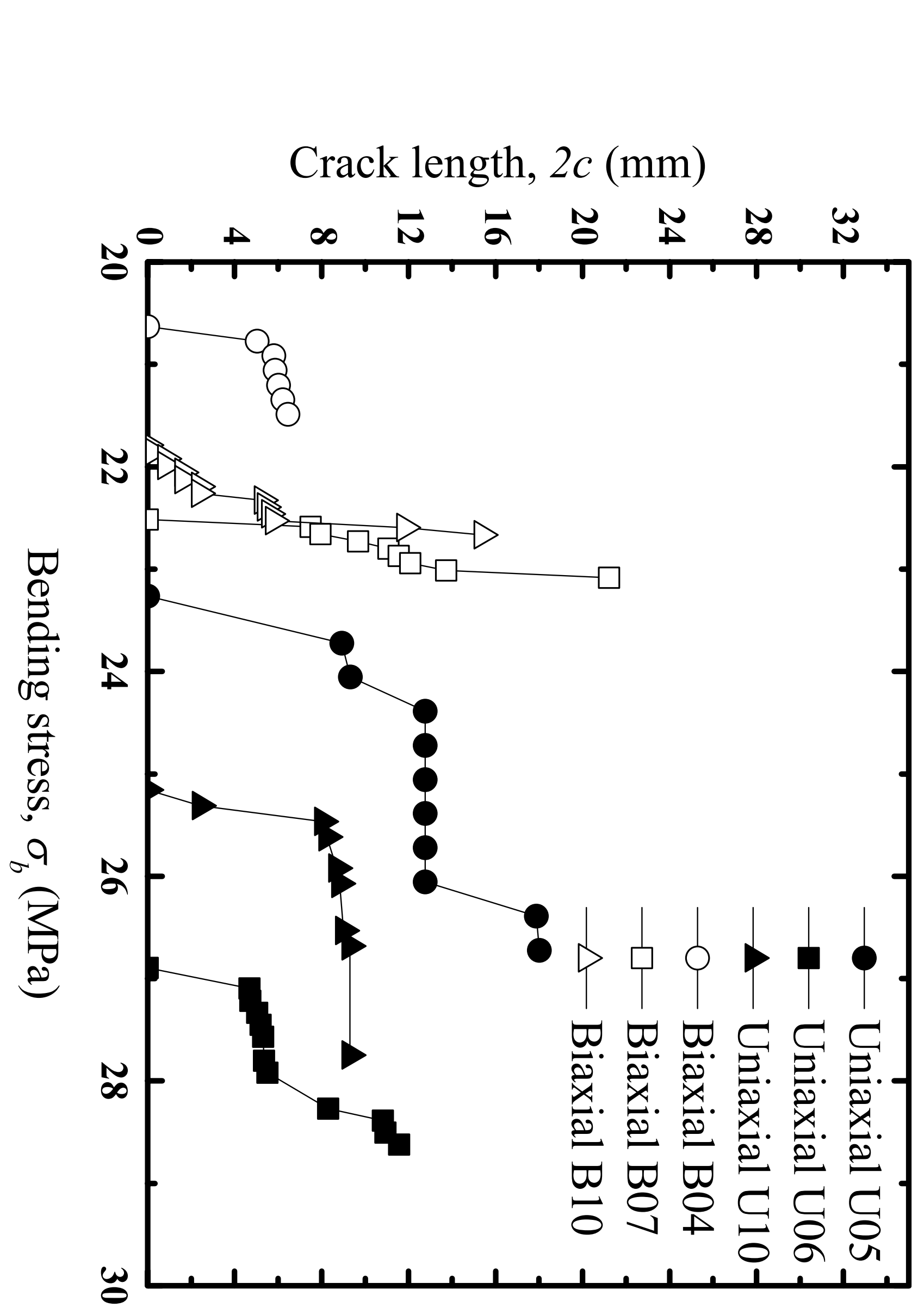

1
0
0
0 


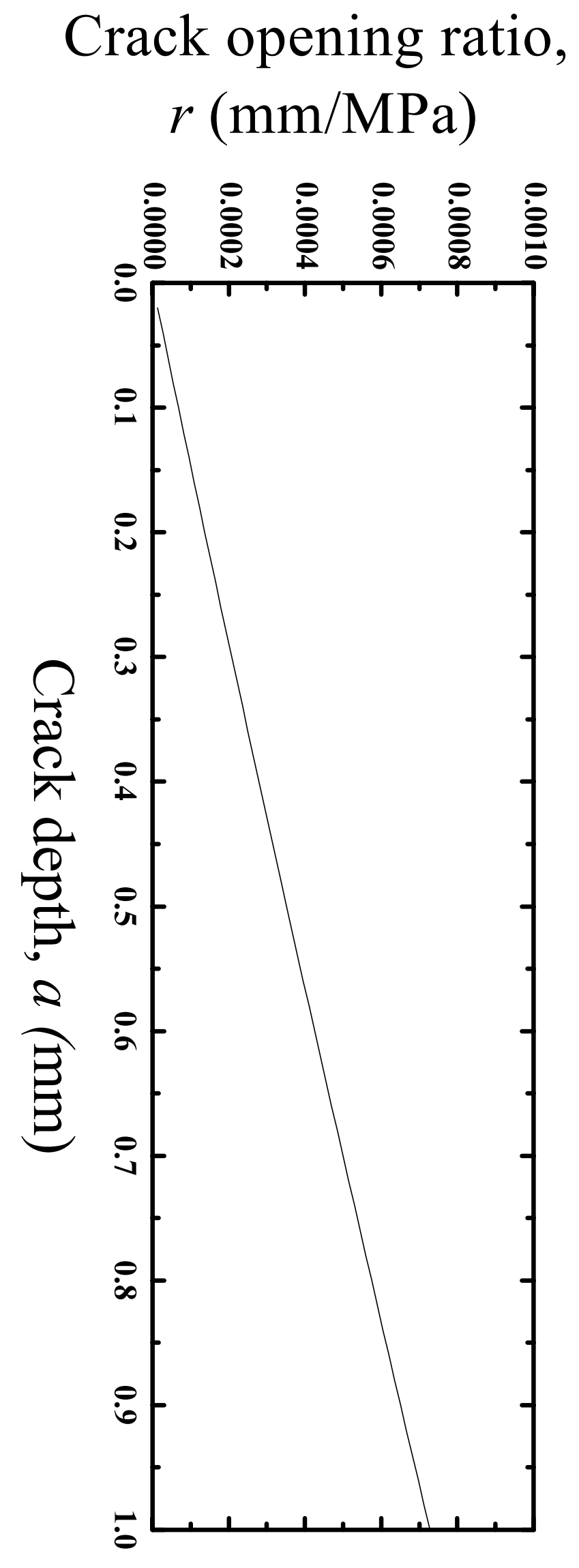

مै 


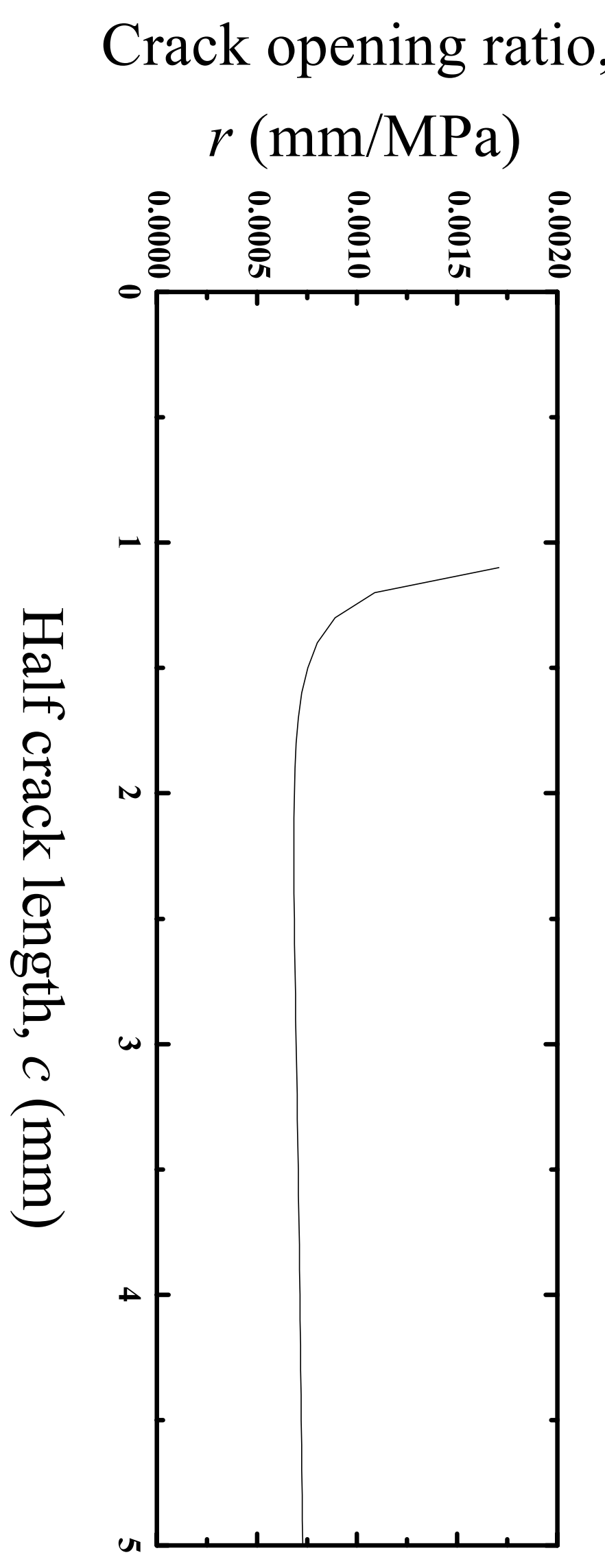

1
0
0
0
0 


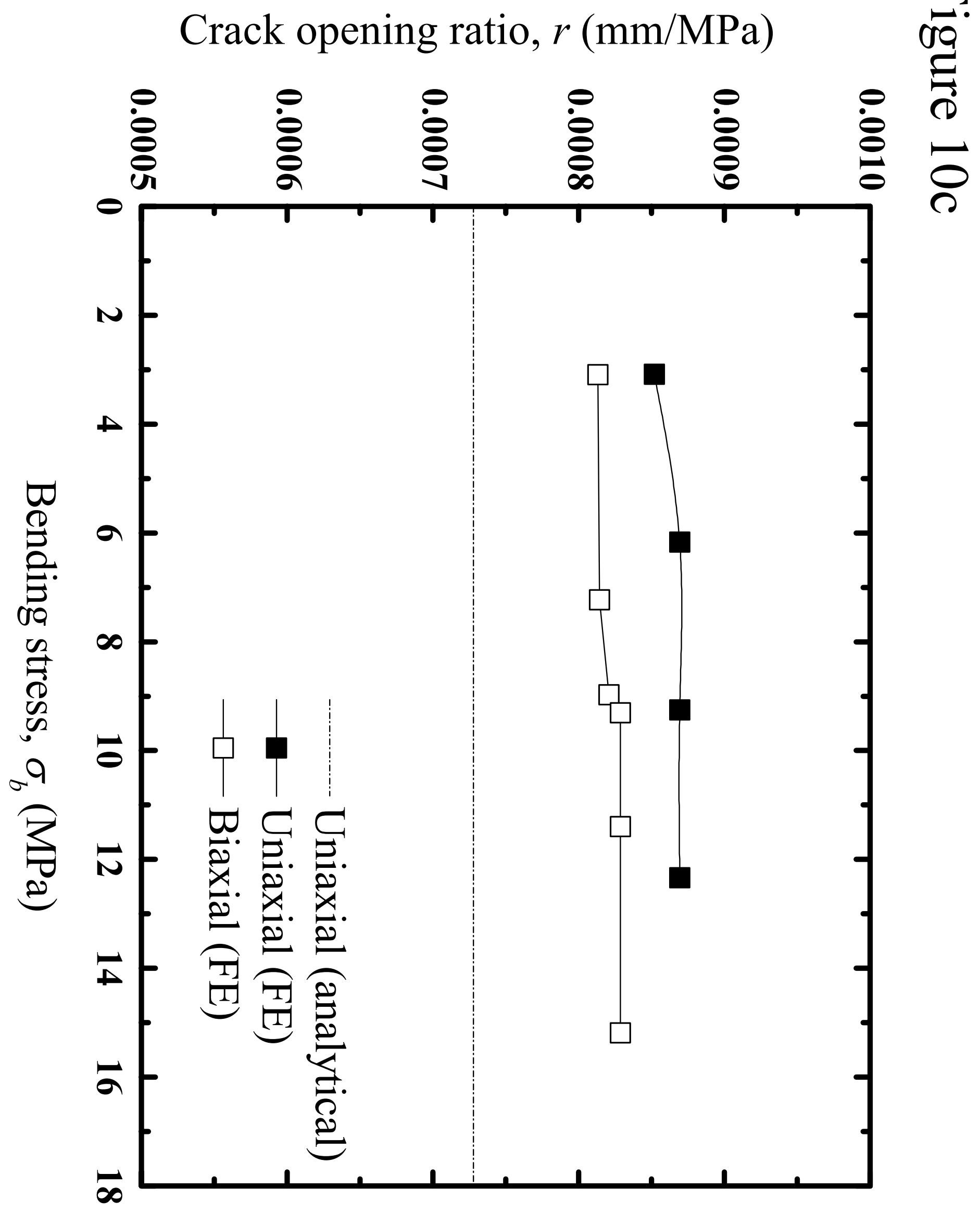


Relative displacement, $D(\mathrm{~mm})$

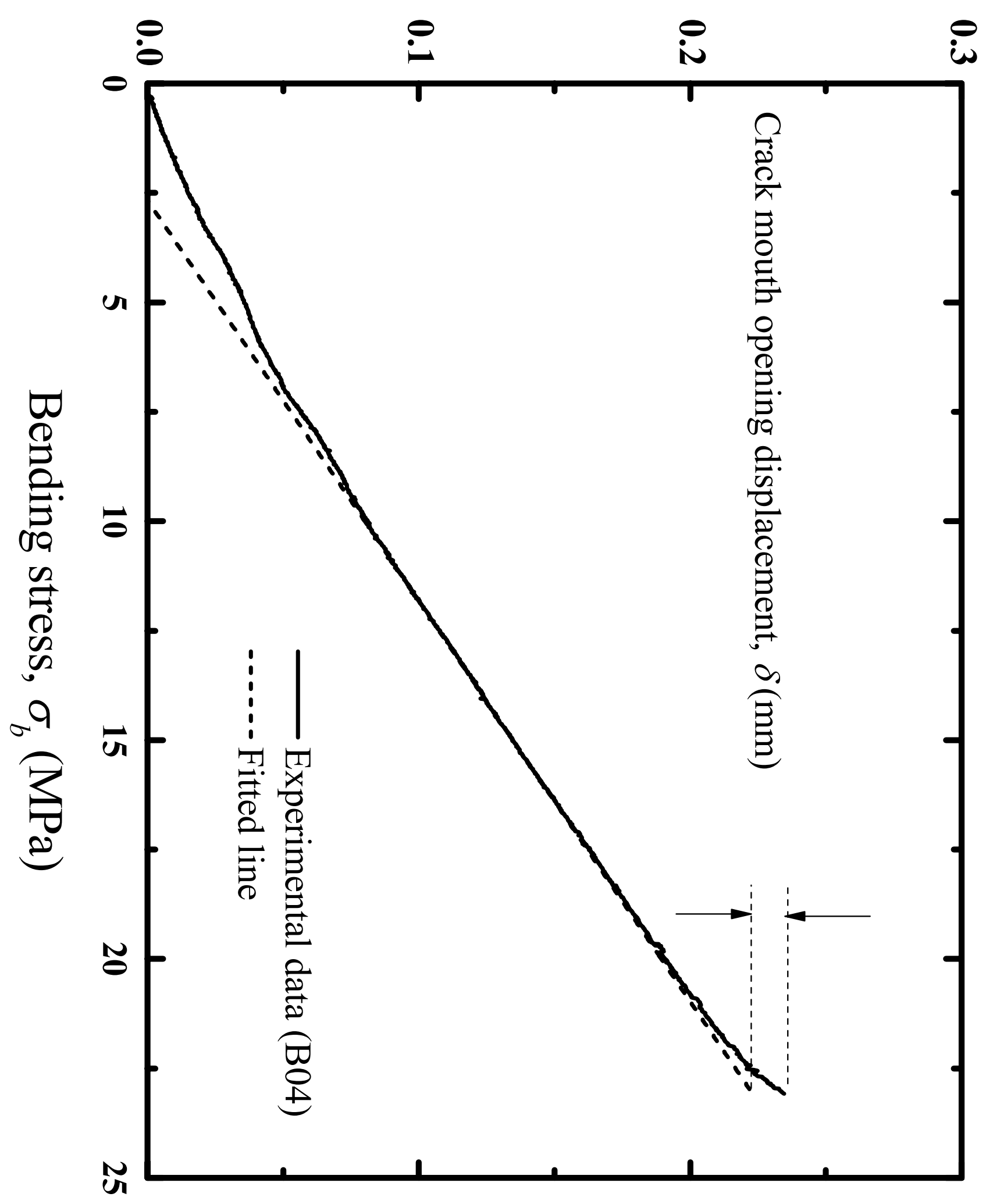




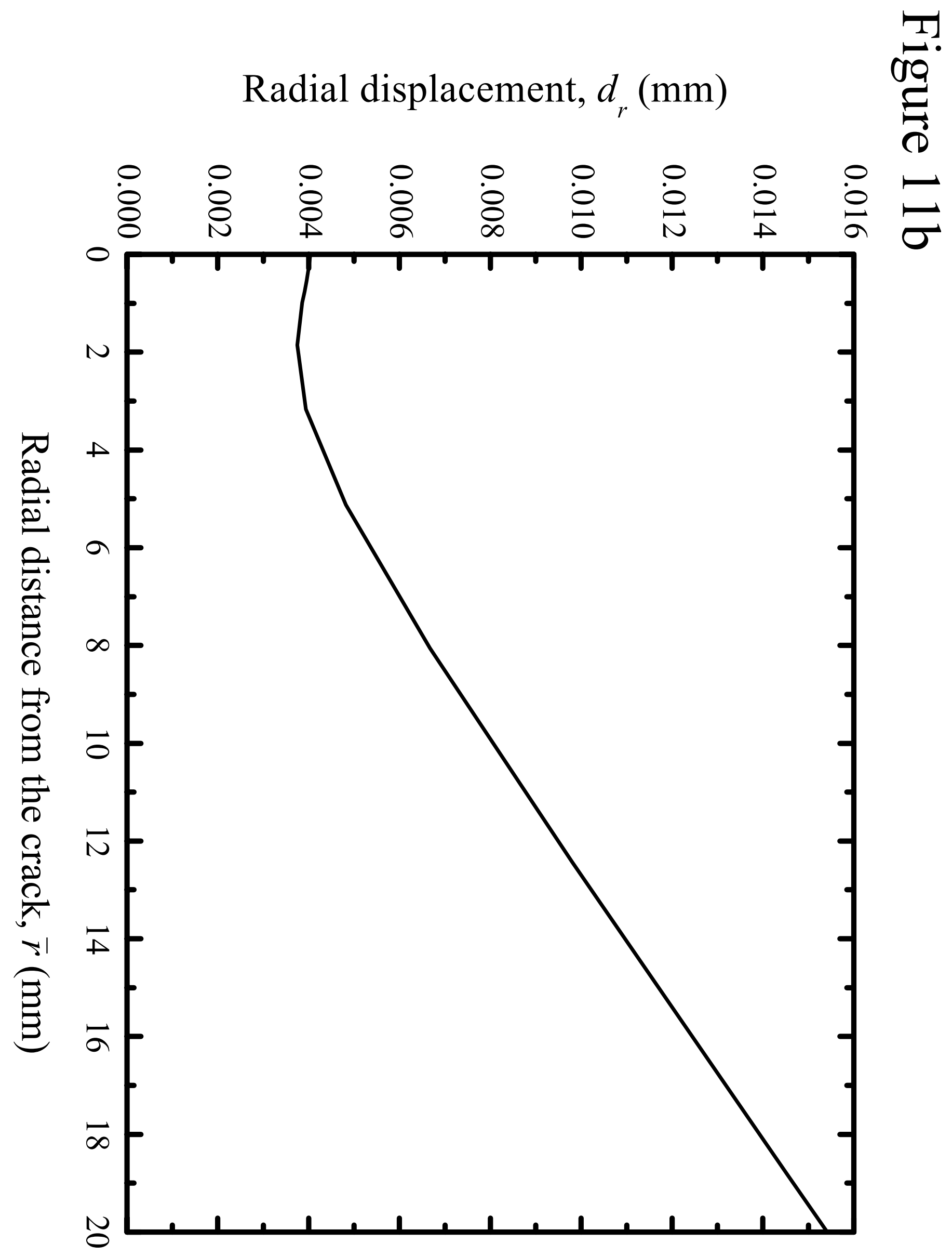




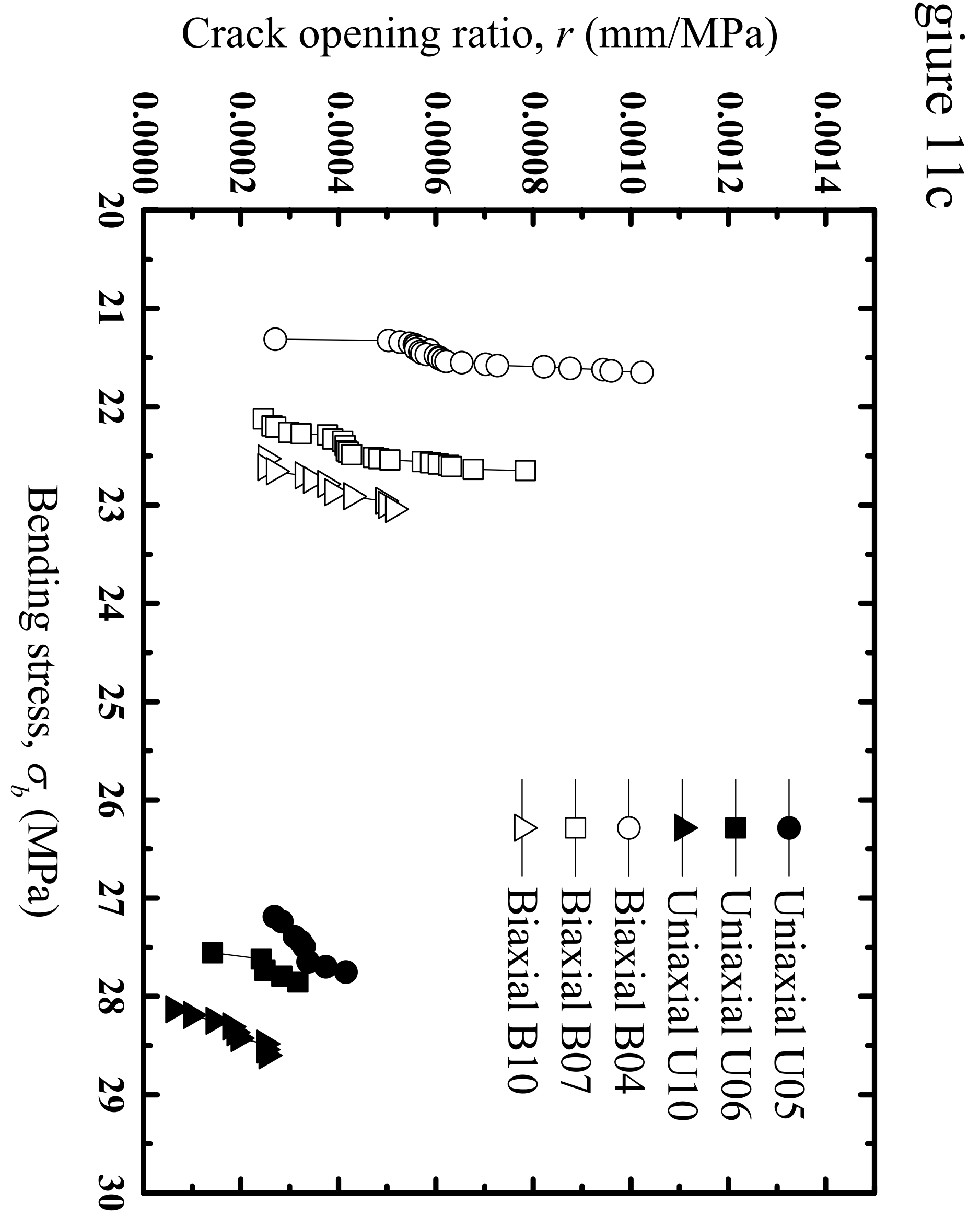




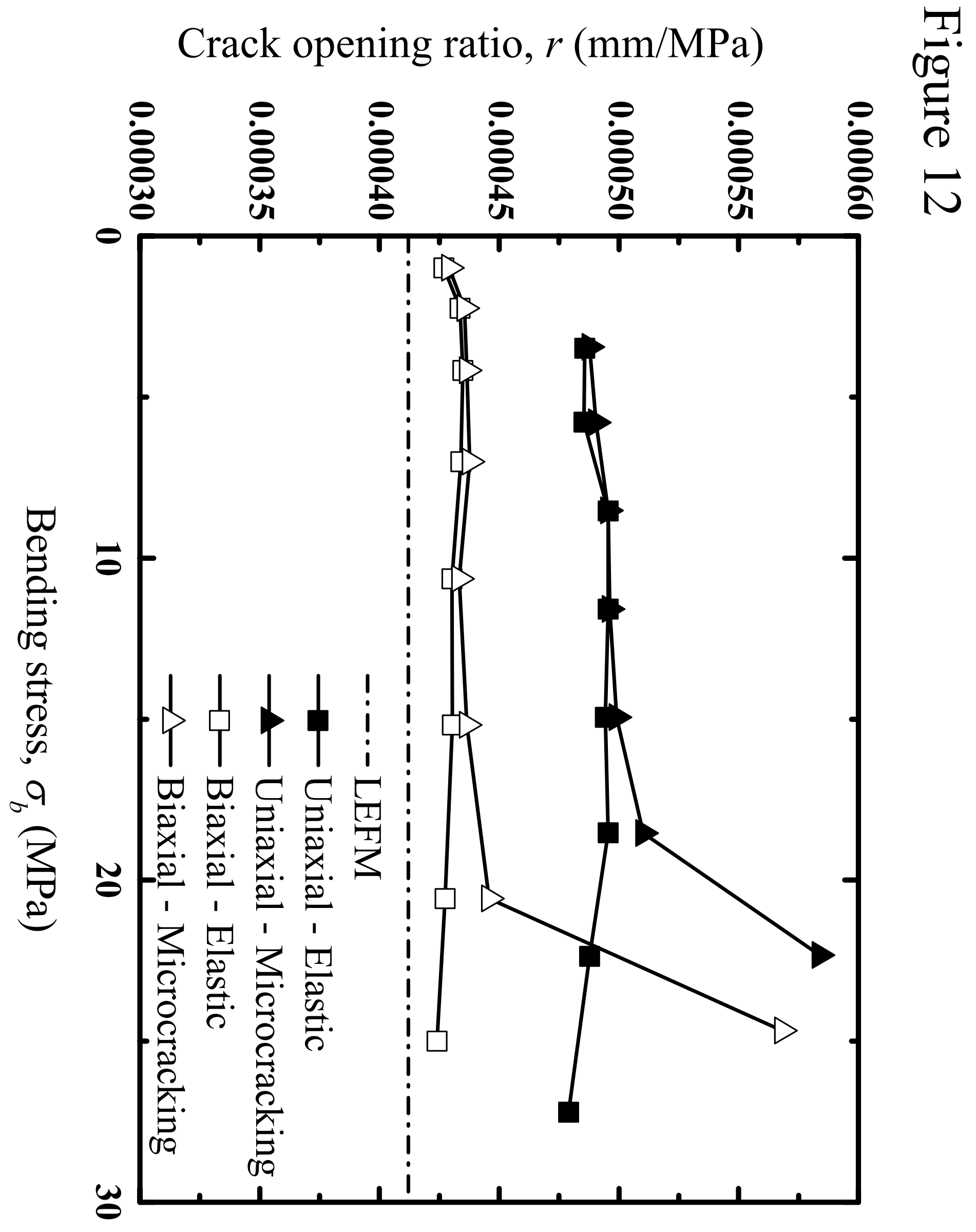

